\title{
A new transcriptome and transcriptome profiling of adult and larval tissue in the box jellyfish Alatina alata: an emerging model for studying venom, vision and sex
}

\author{
Cheryl Lewis Ames ${ }^{1,2^{*}}$, Joseph F. Ryan ${ }^{3,4}$, Alexandra E. Bely ${ }^{5}$, Paulyn Cartwright ${ }^{6}$ and Allen G. Collins ${ }^{1,7}$
}

\begin{abstract}
Background: Cubozoans (box jellyfish) are cnidarians that have evolved a number of distinguishing features. Many cubozoans have a particularly potent sting, effected by stinging structures called nematocysts; cubozoans have well-developed light sensation, possessing both image-forming lens eyes and light-sensitive eye spots; and some cubozoans have complex mating behaviors, including aggregations, copulation and internal fertilization. The cubozoan Alatina alata is emerging as a cnidarian model because it forms predictable monthly nearshore breeding aggregations in tropical to subtropical waters worldwide, making both adult and larval material reliably accessible. To develop resources for $A$. alata, this study generated a functionally annotated transcriptome of adult and larval tissue, applying preliminary differential expression analyses to identify candidate genes involved in nematogenesis and venom production, vision and extraocular sensory perception, and sexual reproduction, which for brevity we refer to as "venom", "vision" and "sex".

Results: We assembled a transcriptome de novo from RNA-Seq data pooled from multiple body parts (gastric cirri, ovaries, tentacle (with pedalium base) and rhopalium) of an adult female A. alata medusa and larval planulae. Our transcriptome comprises $\sim 32 \mathrm{~K}$ transcripts, after filtering, and provides a basis for analyzing patterns of gene expression in adult and larval box jellyfish tissues. Furthermore, we annotated a large set of candidate genes putatively involved in venom, vision and sex, providing an initial molecular characterization of these complex features in cubozoans. Expression profiles and gene tree reconstruction provided a number of preliminary insights into the putative sites of nematogenesis and venom production, regions of phototransduction activity and fertilization dynamics in A. alata.
\end{abstract}

Conclusions: Our Alatina alata transcriptome significantly adds to the genomic resources for this emerging cubozoan model. This study provides the first annotated transcriptome from multiple tissues of a cubozoan focusing on both the adult and larvae. Our approach of using multiple body parts and life stages to generate this transcriptome effectively identified a broad range of candidate genes for the further study of coordinated processes associated with venom, vision and sex. This new genomic resource and the candidate gene dataset are valuable for further investigating the evolution of distinctive features of cubozoans, and of cnidarians more broadly.

Keywords: Cubozoa, Expression patterns, Pedalium, Sting, Embryo, Gametogenesis, Planulae, Eye, Spawning aggregations, Sperm

\footnotetext{
*Correspondence: amesc@si.edu

${ }^{1}$ Department of Invertebrate Zoology, National Museum of Natural History,

Smithsonian Institution, Washington, DC 20013, USA

2Biological Sciences Graduate Program, University of Maryland, College Park,

MD 20742, USA

Full list of author information is available at the end of the article
} 


\section{Background}

Cubozoa (box jellyfish) is a class of Cnidaria with a suite of distinct features including a cuboid bell, lens eyes and a typically highly potent sting. Like many cnidarians, cubozoan life history includes a swimming planula larva that ultimately settles onto a substrate to become an asexually reproducing polyp. Polyps then give rise to medusae (jellyfish), which have separate sexes and are the sexually reproductive stage. Some cubozoan taxa have evolved complex sexual behavior including synchronous spawning aggregations, mating and internal fertilization [1-3]. Cubozoan medusae vary widely in the potency of their sting; in humans, cubozoan stings range from being harmless to causing deadly envenomation [4-7]. A particularly note-worthy character of cubozoan medusae is their image-forming lens eyes, which have been implicated in visually-guided behavior [8-11].

Like all other cnidarians, cubozoans possess nematocysts (stinging organelles) essential for prey capture and defense. Nematocysts are remarkably complex subcellular structures that develop within specialized cells called nematocytes. Nematocysts are secreted from post-Golgi vesicles and consist of a double-walled capsule containing venom and a harpoon-like spiny tubule; and one to several different kinds can develop within a cnidarian throughout its life cycle [12]. Nematocysts are of several forms, broadly divided into penetrant (e.g., euryteles) and adherent (e.g., isorhizas). Penetrant nematocysts are primarily concentrated in the tentacles of cubozoan medusae where they are used for prey capture. In some species, nematocysts are also found in body parts with putative digestive roles, such as the gastric cirri (in the stomach), where they may further immobilize prey items inserted into the cubozoan mouth (manubrium) [13]. Adherent nematocysts are typically found on the exterior of the cubed-shaped bell and do not appear to function in predation there $[14,15]$. The location of nematocyst development (nematogenesis) is poorly known in most cnidarians; having only been well-characterized in the model hydrozoan polyp Hydra, where morphology and molecular studies reveal clusters of developing nematocysts within the body [16]. In contrast, molecular studies of another hydrozoan medusa Clytia, suggest that nematogenic regions are found in the tentacle bulb, proximal to the tentacles in which mature nematocysts are found [17]. Transcriptomic and proteomic studies on the cubozoan Chironex fleckeri, the scyphozoans Chrysaora fuscescens and Stomolophus meleagris, and the hydrozoan Olindias sambaquiensis have focused on characterizing venom components from tentacle components [5, 18-21], but it is unknown whether nematogenesis and venom production occur solely in the medusa tentacles. In A. alata, tiny unidentified nematocysts have been documented within the tentacle base which is contiguous with the pedalium, but it is not clear if these represent an early developmental stage of the larger euryteles that are highly concentrated in the tentacle tips [2]. Studies comparing expression of "venom implicated genes" across medusa body parts can help identify additional putative site(s) of venom production and regions of nematogenesis in cubozoans.

Unique among cnidarians, only cubozoan medusae possess image-forming eyes implicated in visual-guided behavior [8]. Two complex eyes, complete with lens and retina, are located on special sensory structures called rhopalia on each of the four sides of the medusa bell. Each rhopalium also possesses a statocyst (balance organ), and two pairs of ocelli (light receptors) $[8,22]$ that lack a lens, like other simple animal eyes (having a single pigment cell and at least two photoreceptors [23-25]). Molecular components of the opsin-mediated phototransduction pathway have been identified in the rhopalium of the cubozoans Tripedalia cystophora and C. brevipedalia (as Carybdea rastonii) [26, 27], as well as in nonrhopalium medusa tissue, and planulae, which have simple eye spots $[24,27,28]$. Cubozoan planulae eye spots (ocelli) studied in $T$. cystophora are single cell structures containing a cup of pigment and photosensory microvilli, serving as rhabdomeric photoreceptors [24, 25]. Opsins have also been documented in other cnidarians without lens eyes [29-35] suggesting a role in light perception independent of image formation. Studies comparing expression of "vision implicated genes" across medusa body parts with and without eyes, and planula larvae with simple eyes, can help identify molecular components of the opsin-mediated phototransduction pathway in the rhopalium and aide in discovery of putative areas of extraocular photoreception in cubozoans.

Although most cnidarians reproduce sexually by simple broadcast spawning of their gametes (sperm and/or eggs), many cubozoan species engage in complex sexual behaviors including synchronous spawning aggregations, mating and internal fertilization [1-3]. In species with internal fertilization, such as Alatina alata [2] and Copula sivickisi [1], sperm are taken up by the female (as a spermatophore in the latter species), and following fertilization blastulae or planulae are released into the water $[7,36]$. Histological studies have detected a gametogenic differentiation gradient within the gonads of two cubozoan taxa (Copula sivickisi and Carybdea xaymacana) [1, 22, 37], but it is unknown how widespread this process is in cubozoans. Equally elusive is the location of fertilization in cubozoans, although it has been hypothesized to occur in the gastrovascular cavity adjacent to the ovaries in a few species [1, 2]. Comparing expression patterns of "sex implicated genes" in different body parts can help determine whether a gametogenic differentiation gradient is present in additional cubozoan species, and might also aide in pinpointing more precisely the site of fertilization. 
The goals of this study were to identify candidate genes in box jellyfish that may be involved in nematogenesis and venom production, vision and extraocular sensory perception, and sexual reproduction, which for brevity we refer to as "venom", "vision" and "sex" implicated genes. We focused on the species Alatina alata, which provides a number of advantages for molecular investigation of these traits. The distribution of nematocysts has been well-documented in this species [2, 38, 39], and its sting is potent, causing serious human envenomation; like other cubozoans it has both simple and compound eyes on the medusa rhopalia as well as eye spots in planulae (ciliated swimming larvae); and mature medusae of this species form monthly nearshore spawning aggregations at predictable times (8-10 days after the full moon) in Indo-Pacific and Atlantic localities [2, 40, 41]. A. alata medusae have also been documented (as Carybdea alata) in the open ocean at great depths $[2,42]$. The monthly predictability of mature medusae in nearshore waters $[2,43-45]$ and the ability to obtain planulae in vitro make $A$. alata a particularly favorable candidate for a cubozoan model.

RNA-Seq transcriptomics provides a reasonably unbiased method of profiling putative candidate genes in different body parts and life stages. This approach has been used successfully in other cnidarians to identify putative genes involved in different stages of a scyphozoan life cycle [46] and in different polyp types in a colony hydrozoan [47]; to identify candidate venom genes in anthozoans [48] and in the tentacles of venomous scyphozoans and cubozoans [5, 19]; and for reconstructing evolutionary relationships within Cnidaria [49]. In the absence of a reference genome for A. alata, we generated a de novo transcriptome assembly pooled from RNA-Seq data from specific body parts (gastric cirri, tentacle-including the base of the adjoining pedalium, rhopalium, and ovaries) of a female medusa undergoing internal fertilization during a spermcast mating event. We compared these transcripts to known eukaryote gene and protein databases, and identified genes implicated in venom, vision and sex based on homology and tissue-specific gene expression profiles. We also investigated the expression of these candidate genes in planulae. Presented here is the first functionally annotated transcriptome of $A$. alata, which serves as a valuable resource for understanding the molecular underpinnings of cubozoan biological processes and their mediation of complex behaviors.

\section{Results}

Sample collection

Alatina alata material was collected during a spermcasting aggregation in Bonaire, The Netherlands (April 23-25, 2014, 22:00-01:00) according to the methods in [2].
A single ovulating female medusa (Fig. 1a) was dissected to provide four tissue samples, namely: i. gastric cirri (Fig. 1b), ii. ovaries (Fig. 1c) (within gastrovascular cavity filled with sperm (Fig. 1d)), iii. tentacle (containing nematocysts Fig. 1e) and adjoining pedalium base, which we refer to collectively as the "tentacle sample" below (Fig. 1a), and iv. rhopalium (including rhopaliar stalk) (Fig. 1f). A fifth sample consisted of planulae (Fig. 1h) that developed from blastulae (Fig. 1g) released by females in the lab. Transcripts putatively involved in venom were characterized through their apparent up-regulation in the tentacle and gastric cirri samples; transcripts putatively involved in vision were targeted through analysis of the rhopalium sample; and transcripts putatively involved in sex and embryogenesis were investigated through analysis of the ovaries and planulae samples. We sought to identify the possible onset of expression of candidate genes in the larval planula stage. Given the microscopic size $(\sim 150 \mu \mathrm{m})$ of the planulae, multiple individuals were pooled to obtain sufficient tissue for RNA isolation and sequencing. Detailed protocol is provided in Methods.

\section{RNA-Seq and bioinformatics De novo transcriptome assembly}

RNA-Seq was performed on five different tissues using the Illumina HiSeq2500 Sequencing System (see Methods). Using Trinity software $[50,51]$ the $\sim 264$ million trimmed raw paired-end sequence reads were assembled de novo into a pooled transcriptome yielding $~ 126$ KTrinity transcripts corresponding to $\sim 84 \mathrm{~K}$ Trinity genes with an N50 of 1994 (Table 1). Throughout this paper, we use the term "A. alata gene" to refer to each transcriptome component represented by a unique Trinity gene id, and the term " $A$. alata transcript" to refer to additional transcriptome components that Trinity assigned as multiple putative "isoforms" of a single unique gene id [50, 51]. Transcriptome completeness was assessed using the subset of 248 widely conserved eukaryote core genes (with low frequency of gene family expansion) using the program CEGMA (Core Eukaryotic Genes Mapping Approach) [52, 53]. We retrieved 242 complete CEGs (98\%) and an additional three partial CEGs (1\%), resulting in 99 \% CEG representation. We sought to identify highly expressed transcripts which, by definition, are represented by more reads (than lowly expressed transcripts), and thus have a better chance of being contiguously assembled. Therefore we generated a filtered transcriptome comprising a subset of transcripts expressed above a minimum threshold of 1.5 fragments per kilobase per million fragments mapped (fpkm) [46], based on read quantification and alignment accuracy using RSEM [54]. This filtering step is consistent with our aim of identifying highly expressed transcripts for potential candidate genes across different samples types. The filtered transcriptome, 


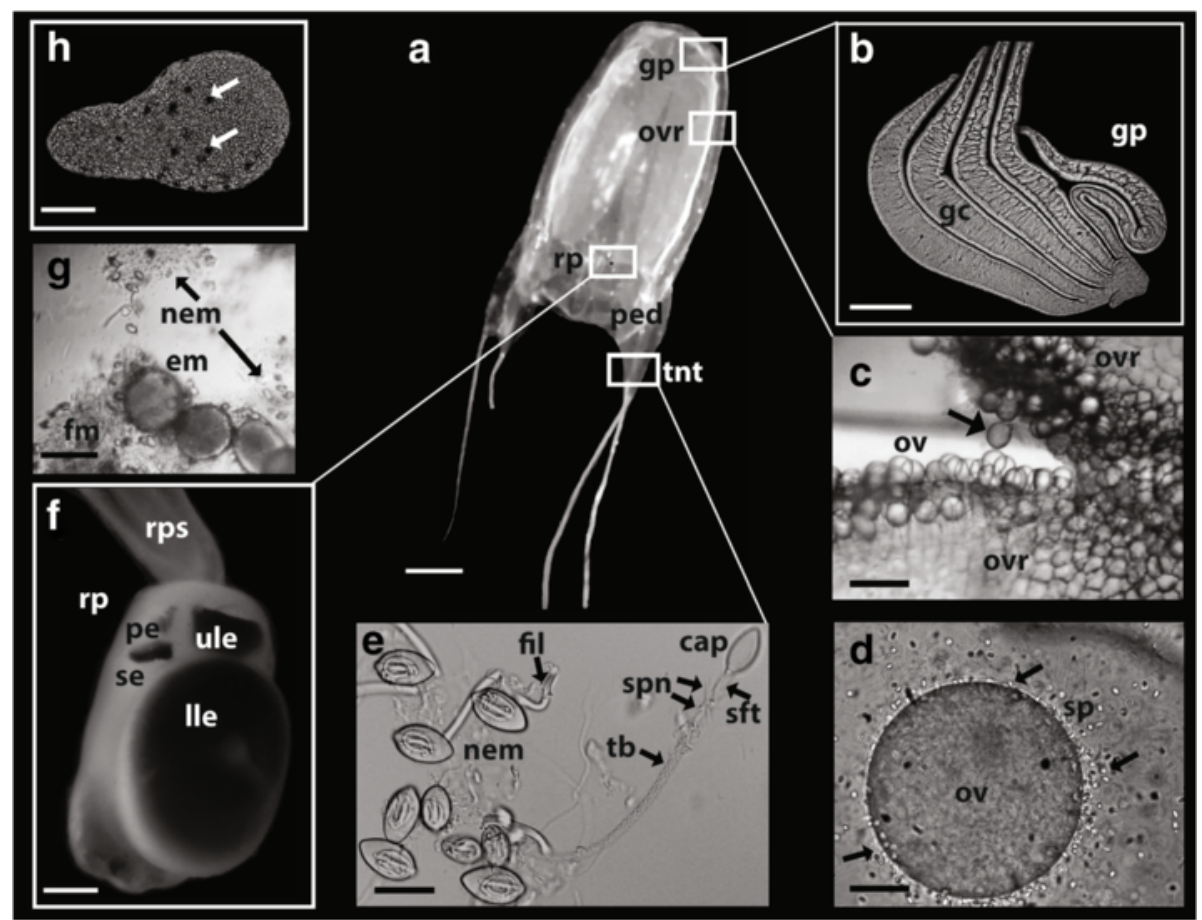

Fig. 1 a-h Morphology of A. alata mature female medusa similar to that collected and subsampled for de novo transcriptome assembly in this study. White boxes correspond to the location of medusa body parts sub-sampled. a Mature A. alata medusa (live). b A portion of a gastric phacella removed from a live medusa, with five individual gastric cirri. c Ovulation documented within the female gastrovascular cavity; arrow indicates imminent release of teardrop shaped ovum. $\mathbf{d}$ Interaction between recently ovulated egg and spermatozoa (arrows) in the fluid examined from the gastrovascular cavity (representing putative fertilization). e Intact nematocysts (euryteles with associated filaments) on the left, and a discharged eurytele on the right, isolated from the tentacle. $\mathbf{f}$ Rhopalium connected to the rhopaliar stalk showing upper and lower lens eyes, and lateral pit and slit eyes (one of each pair visible). $\mathbf{g}$ Bundles of blastulae released by females entangled in fibrous material and intact eurytele nematocysts. $\mathbf{h}$ Swimming planula (within $20 \mathrm{~h}$ of blastula release from the female); arrows indicating planulae eyes spots. Abbreviations: cap = capsule of nematocyst; em =embryos; fil = filaments; $\mathrm{fm}$ = fibrous material, $\mathrm{gc}=$ gastric cirri; $\mathrm{gp}=$ gastric phacella (comprised of numerous gastric cirri); nem = nematocyst (birhopaloids)s; ov = ovum (ova); ovr = ovaries; $\mathrm{pe}=$ pit eye; ped = pedalium; $\mathrm{rp}=$ rhopalium; $\mathrm{rps}=$ rhopaliar stalk; se = slit eye; $\mathrm{sp}=\mathrm{sperm}$; sft = shaft of nematocyst tubule; $\mathrm{spn}=$ spines of nematocyst shaft; $\mathrm{tb}=$ tubule of discharged nematocyst; tht $=$ tentacle. Scale bars: $\mathrm{a}=\sim 15 \mathrm{~mm}, \mathrm{~b}=\sim 0.5 \mathrm{~mm}, \mathrm{c}=\sim 250 \mu \mathrm{m}$, $\mathrm{d}=\sim 30 \mu \mathrm{m}, \mathrm{e}=\sim 20 \mu \mathrm{m}, \mathrm{f}=\sim 0.2 \mathrm{~mm}, \mathrm{~g}=\sim 100 \mu \mathrm{m}, \mathrm{h}=\sim 30 \mu \mathrm{m}$

hereafter referred to simply as the $A$. alata transcriptome, yielded $\sim 32 \mathrm{~K}$ transcripts corresponding to $\sim 20 \mathrm{~K}$ genes; N50 $=2545$ (Table 1). The percentage of sequences above $1000 \mathrm{bp}$ doubled and the percentage of short genes (200-500 bp) was reduced by half (Additional file 1). Figure 2 illustrates the workflow used in this study (modelled after [47]).

\section{Functional annotation}

Our first objective was to annotate the A. alata transcriptome. The longest open reading frames (ORFs) were predicted for transcripts using TransDecoder [50] and subsequently annotated with Trinotate [51], which compiles results of homology searches of reliable databases (i.e., Uniprot; NCBI; eggNOG/GO; HMMER/PFAM, SingalP) to capture Basic Local Alignment Search Tool (BLAST) protein and gene homologies. The resulting Trinotate report for the $\sim 32 \mathrm{~K} A$. alata transcripts contained 12,317 BLASTP top hits from TrEMBL and 10,627 BLASTP top hits from SwissProt, from which 656 candidate genes were examined in this study for their putative roles in venom, vision and sex (see Candidate gene profiling below). In total 96 of the top 100 most abundant genes in the transcriptome (based on normalized counts) were assigned at least one Trinotate annotation category: $85 \%$ of those had BLAST top hits; and $63 \%$ corresponded to candidate genes we explored as implicated in either venom, vision or sex in this study (Additional file 2). The Trinotate report listed 14,551 transcripts corresponding to peptides based on TransDecoder predicted ORFs; 2098 transcripts with transmembrane protein domains (TMHMM database); 1610 transcripts containing the classical secretory signal peptide (SignalP database); and 5252 TrEMBL BLASTP top hits corresponded to cnidarian proteins (Additional file 3).

\section{Gene expression patterns and profiles}

We then sought to detect gene expression patterns across the five samples (gastric cirri, ovaries, tentacle 
Table 1 A. alata pooled transcriptome assembly statistics

\begin{tabular}{lll}
\hline & $\begin{array}{l}\text { Whole } \\
\text { transcriptome }\end{array}$ & $\begin{array}{l}\text { Filtered transcriptome } \\
\text { (fpkm =1.5) }\end{array}$ \\
\hline No. of transcripts & 126,484 & 31,776 \\
$\begin{array}{l}\text { No. of genes } \\
\text { Total assembled }\end{array}$ & 84,124 & 20,173 \\
bases (bp) & $125,647,941$ & $48,556,932$ \\
Avg (mean) transcript & 993 & 1528 \\
length (bp) & & \\
$\begin{array}{l}\text { Median transcript } \\
\text { length (bp) }\end{array}$ & 456 & 989 \\
$\begin{array}{l}\text { Max transcript } \\
\text { length (bp) }\end{array}$ & 9993 & 9993 \\
N50 & 1994 & 2545 \\
GC content (\%) & 39 & 40 \\
Percent proper pairs & 77 & 78 \\
Samtools percent mapped & 75 & 77 \\
and paired & & \\
\hline
\end{tabular}

De novo assembly began with 264,505,922 trimmed raw reads generated from medusa gastric cirri, ovaries, tentacle (with pedalium base), rhopalium, and planulae samples

with pedalium base, rhopalium, and planulae) with the aim of providing a descriptive analysis of the top expressed gene clusters by sample. In order to estimate transcript abundance we aligned each set of reads back to the A. alata transcriptome and generated an RNASeq fragment counts matrix for each sample using RSEM [54]. We subsequently identified differentially expressed genes (see Methods) which we clustered according to their expression profiles using hierarchical clustering analyses within the framework of the EdgeR Bioconductor software package [55], a preferred methodology for studies lacking biological replicates $[46,56]$. Of the $\sim 32 \mathrm{~K}$ Trinity transcripts ( $\sim 21 \mathrm{~K}$ Trinity genes) identified in the $A$. alata transcriptome $\sim 10 \mathrm{~K}$ transcripts (6676 genes) were found to be differentially expressed, within a broad range, across the five samples (Additional file 4). EdgeR takes the normalized gene counts for all samples (generated from the initial RSEM counts matrix), and then clusters genes with similar mean expression rates across samples [56]. Gene clusters are visualized in the form of a heatmap, permitting pinpointing of genes abundant in certain samples that might be of interest as candidate genes. The results of hierarchical clustering were consistent with our initial RSEM evaluation of abundant genes by sample.

In an attempt to identify genes that were specifically abundant in each medusa sample, we conducted subsequent hierarchical clustering with the planulae sample excluded. EdgeR analyses of genes from just the four medusa samples (gastric cirri, ovaries, tentacle (with pedalium base) and rhopalium) revealed 2916 differentially expressed genes. To identify patterns of highly expressed gene clusters by medusa sample, we generated a heatmap of the subset of 2916 genes and further partitioned the subset into 10 gene subcluster profiles based on mean expression patterns across samples (Fig. 3a-k; Additional file 5). Furthermore, redoing the hierarchical clustering and subcluster profiling analyses for all five samples using the three subsets of candidate genes (putative venom, vision and sex genes) allowed us to hone in on gene clusters that were relevant to transcriptome functional annotation and profiling of different $A$. alata samples.

\section{Tissue-specific "core genes"}

Our next objective was to identify specific genes that are highly expressed in particular body parts (abundant with respect to other samples), and subsequently identify functional categories informed by the Trinotate report. We constructed a Venn diagram of the 2916 differentially expressed genes from the four medusae samples (Fig. 4a), which revealed that $76 \%$ (2228 genes) were expressed to some degree in all medusa samples (Additional file 1). A subset corresponding to the top 50 most highly expressed genes per sample was plotted in a second Venn diagram (Fig. 4b), and genes unique to each sample's top 50 were respectively designated as that sample's "core genes" (Additional file 6). Only one gene (lacking a Trinotate annotation) among each sample's top 50 most highly expressed genes overlapped in all four samples. An assessment of the core genes revealed that only about $40 \%$ had Trinotate-generated annotations (Fig. 5a-d). Gastric cirri core genes $(n=46)$ corresponded mostly to putative proteins ( 26 annotations) implicated in venom and digestion, including metalloproteinases (Fig. 5a) [5, 57, 58]; ovaries core genes (n =33) corresponded to putative proteins (22 annotations) involved in gametogenesis, including Vitellogenins (Fig. 5b), which, although well studied in bilaterians [59], are newly reported in cubozoans herein; tentacle core genes $(n=34)$ corresponded to many putative proteins (19 annotations) associated with nematocyst development, including minicollagens (Fig. 5c) [60-62]; and rhopalium core genes $(n=20)$ corresponded to several putative proteins (12 annotations) identified in vision and the phototransduction pathway, including J-crystallins (Fig. 5d) [28, $33,63]$.

\section{Candidate gene profiling}

Using the tissue-specific core gene annotations (see above) as a starting point for identifying candidate genes in $A$. alata medusa body parts, we compiled three candidategene lists comprising 148, 109 and 39 terms (related to genes and/or gene functions) broadly associated with "venom", "vision", and "sex", informed primarily by relevant genes and proteins documented in the scientific literature (Additional files 7, 8 and 9: provides lists of terms, 


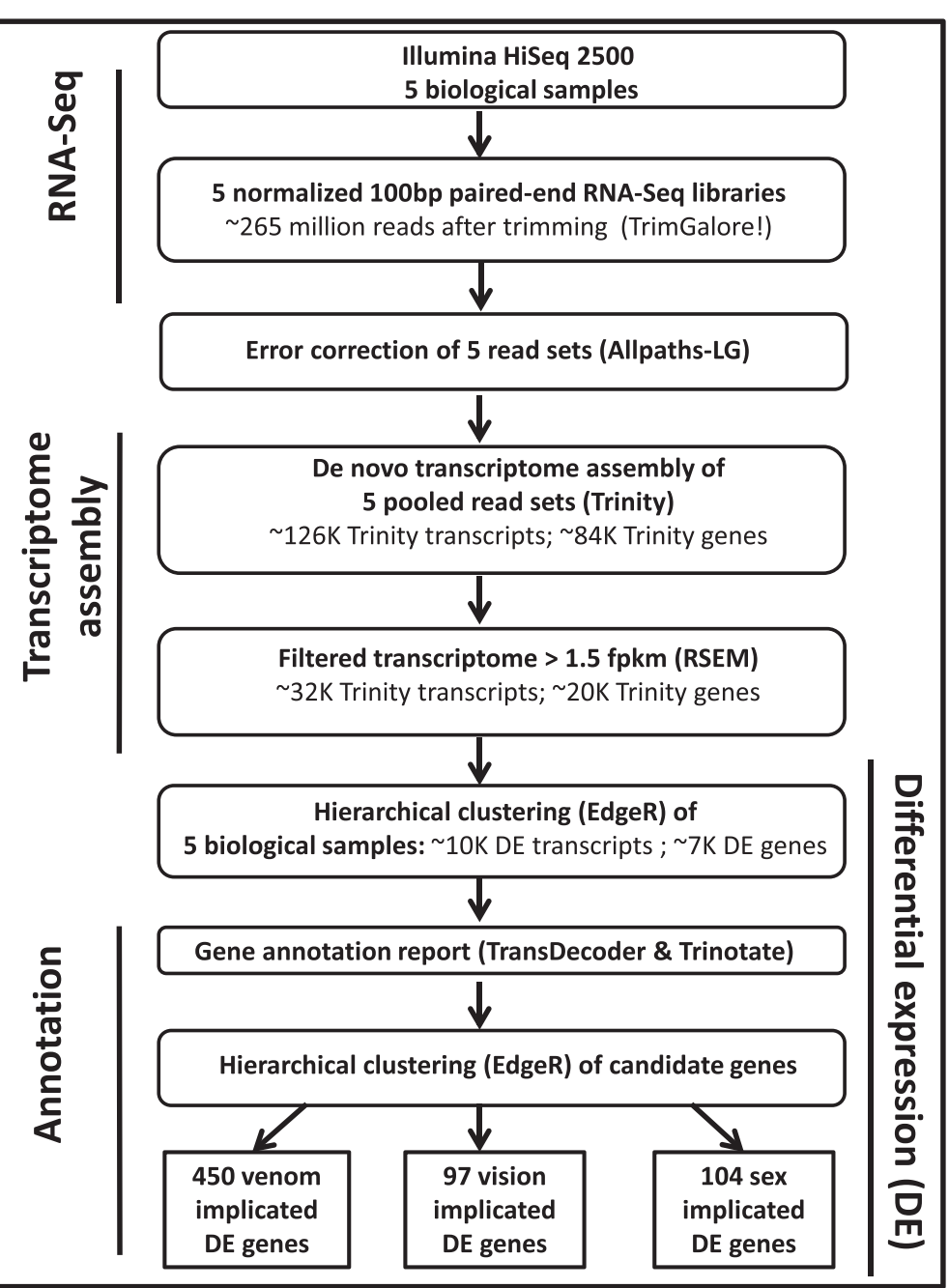

Fig. 2 Flowchart of methodology used in transcriptome assembly, gene annotation and differential expression of the five A. alata samples analyzed in this study. Additional details provided in Results and Methods. Figure modelled after [47]

references and differential expression matrices for all putative candidate genes). Subsequently, we queried the $A$. alata Trinotate report separately using each of the lists to identify matching terms among BLASTX, BLASTP and PFAM (protein family) top hits from the Trinotate transcriptome annotation report. This generated three additional targeted Trinotate annotation reports consisting of gene subsets we categorized as "venom implicated genes" (Additional file 7), "vision implicated genes" (Additional file 8), and "sex implicated genes" (Additional file 9). Subsequently, EdgeR hierarchical clustering (see above) was conducted separately on each subset of corresponding candidate genes, generating three new heat maps (Figs. 6, 7 and 8); profiling the respective patterns of expression of each set of candidate genes across all five samples. In all cases, gene cluster patterns were divided into 10 subclusters based on mean expression patterns for genes with potential association with venom $(n=450)$ (Fig. 6b-k); vision $(n=97)$ (Fig. 7b-k); and sex $(n=104)$ (Fig. 8b-k). By comparing planulae samples with samples from body parts of the mature female medusa, an additional aim of this study was to detect the potential onset of expression of these possible candidate genes within developing planulae. Differential expression matrices for all candidate genes and their respective annotations are provided in Additional files 7, 8 and 9. We did not detect expression of most candidate genes in the planulae sample. Instead, we found that transcripts most highly expressed in the planulae comprised mainly: histones (core and early embryonic), nanos transcription factor, and genes implicated in neurogenesis, mitosis, microtubule, and protein processing (Additional file 10).

Putative venom implicated genes Here we highlight our findings of the 450 transcripts we broadly refer to as 

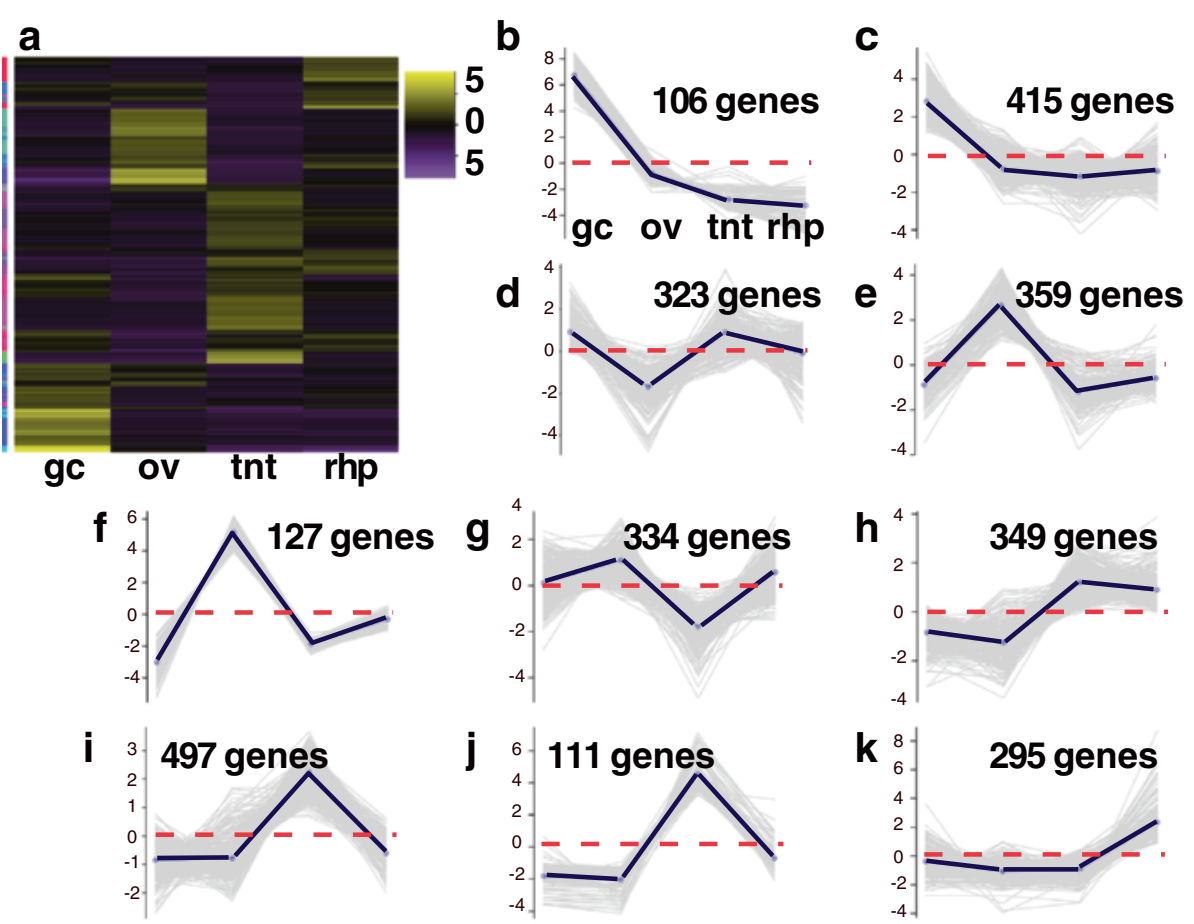

Fig. 3 a-k Heatmap of A. alata medusa samples. Hierarchical clustering (EdgeR) and corresponding ten subcluster profiles for the 2916 genes differentially expressed across A. alata medusa samples (gastric cirri, ovaries, tentacle (with pedalium base), rhopalium) (of the identified $\sim 20 \mathrm{~K}$ Trinity genes. Intensity of color indicates expression levels for each of the ten hierarchical clusters (vertical access). Bright yellow patches correspond to the highest peaks for each $\mathrm{k}$ mean subcluster profile. K-mean profiles (b-k) match the order of column names in $\mathbf{a}$, representing the mean expression of gene clusters highly abundant in each sample (centroid demarcated by the solid line; zero indicated by the horizontal dashed red line). Three bright yellow transcript clusters in the gastric cirri column correspond to each of the peaks seen in plots $\mathbf{b}, \mathbf{c}$ and $\mathbf{d}$ in the ovaries column correspond to plots $\mathbf{e}, \mathbf{f}, \mathbf{g}$ and in the tentacle column correspond to $\mathbf{h}, \mathbf{i}, \mathbf{j}$, while the two bright yellow clusters in the rhopalium column correspond to peaks in plots $\mathbf{k}$, and to the less prominent peaks in plots $\mathbf{g}$ and $\mathbf{h}$. The vertical colored bar on the left of the heatmap (a) indicates distinct patterns corresponding to the ten subcluster profiles ( $\mathrm{sc}=\mathrm{subcluster}$ number), for which the number of genes each comprises is indicated. Abbreviations: $g c=$ gastric cirri, ov $=$ ovaries, tht $=$ tentacle (and pedalium base), rhp $=$ rhopalium, and pln = planulae. (Original matrix in Additional file 5)

"venom implicated genes" based on preliminary candidate gene profiling (above). This effort focused specifically on identifying genes highly expressed in the tentacle (used in prey capture) and gastric cirri (used in digestion). By comparing a body part with tissue abundant in penetrant nematocysts (tentacle and adjoining pedalium base) (Fig. 1e) with one lacking nematocysts (gastric cirri Fig. 1b) our aim was to identify putative site(s) of venom production and nematogenesis in A. alata. Although nematocysts are typically abundant in the gastric cirri of many box jellyfish species [15], only a single individual nematocyst has been documented in the gastric cirri of mature A. alata medusae [2] despite examination of hundreds of mature specimens in several independent studies [2, 15, 38, 40]. Conversely, nematocysts (Fig. 1e) are primarily concentrated in the tentacle (which is contiguous with the pedalium) of $A$. alata [2], as is the case with all cubozoans [15]. Hierarchical gene cluster profiling (Fig. 6 a-k) revealed that many of the putative venom implicated genes were fittingly highly expressed in the tentacle (Figs. 5c and 6e-i), but were surprisingly also highly abundant in the gastric cirri (Figs. 5a and 6b,c; Additional file 7).

\section{CaTX/CrTX toxin family genes}

We identified eleven different homologs of the CaTX/ CrTX toxin family (also annotated individually as CrTXA or CaTX-A). These were either abundant almost exclusively in the tentacle $(n=4)$ (Figs. $5 \mathrm{c}$ and $6 \mathrm{e}, \mathrm{f})$ or in the gastric cirri $(n=7)$ (Figs. $5 \mathrm{a}$ and $6 \mathrm{~b}, \mathrm{c})$. This gene family consists of pore-forming toxins that cause pain, inflammation and necrosis during human envenomation [64] and prior to this study has exclusively been associated with venom from nematocysts $[18,19,65]$. The taxonomically restricted CaTX/CrTX toxin family $[66,67]$, previously called the "box jellyfish toxin family" [64, 66, 67], was thought to be restricted to medusozoans [5], but recently a homolog was also identified in the anthozoan coral Acropora [68]. Gene tree reconstruction (Fig. 9) of the eleven CaTX/CrTX gene homologs abundant in either the gastric cirri or the tentacle confirmed 

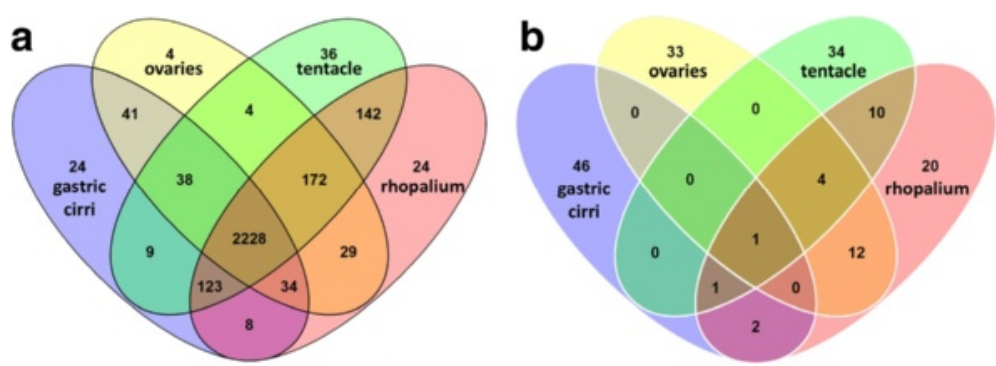

Fig. 4 a, b Venn diagrams showing overlap of genes differentially expressed exclusively in A. alata medusa samples (gastric cirri, ovaries, tentacle, rhopalium). a Shows that of the 2916 total genes differentially expressed across the four samples 2228 (76 \%) are expressed in all samples, 24 are unique to gastric cirri, 4 are unique to ovaries, 38 are unique to the tentacle, and 24 are unique to the rhopalium. $\mathbf{b}$ Shows that of the top 50 most highly differentially expressed genes by sample type, a single gene is expressed in all four samples. The subset of genes unique to the top 50 most abundant genes by sample, called the "core genes" herein, comprises 46 genes in the gastric cirri, 33 in the ovaries, 34 in the tentacle (and pedalium base), and 20 in the rhopalium. Core gene annotations provided in Additional file 6 and summarized in histograms Fig. 6a-d

homology of the $A$. alata transcripts with CaTX/CrTX toxin family genes in other cnidarians $[5,19,68]$. The analysis recovered four well-supported groups of $A$. alata CaTX/CrTX genes, each exclusively containing transcripts with tissue-specific expression patterns, either in tentacle or gastric cirri (Fig. 9). One group includes three A. alata homologs (annotated as CaTX/CrTX, CaTX or CrTX) specific to the tentacle that group with several non-cubozoan medusozoans including the coral Acropora. Three additional groups are all within a well-supported cluster of CaTX/CrTX genes identified from cubozoan taxa. One of these nested groups includes the homolog (CaTX-A) reported more than a decade ago [65] in $A$. alata (as Carybdea alata). Homologs of this gene are sister to a sub-group comprised of Chironex fleckeri homologs, which have been identified exclusively from tentacle tissue. The two additional nested groups (Fig. 9) include the homolog (CrTX-A) reported more than a decade ago in Carybdea brevipedalia (reported as $C$. rastonii), consisting of transcripts only identified in our gastric cirri sample, in a well-supported cluster of homologs derived from Carybdea brevipedalia and Malo kingi. Ours is the first report of expression of the CaTX/CrTX toxin family in a medusozoan body part that lacks nematocysts.

\section{Venom components}

We report that an abundance of "cysteine-rich secretory protein family" (CRISPs) transcripts occurred almost exclusively in either the gastric cirri or the tentacle. Some examples include: "serine protease coagulation factor vii", "chymotrypsin-like elastase family" homologs, and "serine protease inhibitor" (Figs. 5a and 6c). Likewise, multiple homologs of the "zinc metalloproteinase/astacin (peptidase family m12a)" (Figs. 5a, c and 6b, c, f, i, k) were primiarily abundant in the gastric cirri, but with high expression in the tentacle as well. Zinc metalloproteinases are peptidases with known roles in venom maturation in spiders and snakes, and were recently identified as tentacle venom components of some jellyfish taxa $[5,18,58]$. Conversely, homologs of wellknown bilaterian venom proteins (e.g., pit viper (Croatulus)/zinc metalloproteinase nas-4/venom factor (Fig. 6i); scorpion (Lychas), venom protein 302 (Fig. 6h); the "venom prothrombin activator pseutarin-c non-catalytic subunit" from the eastern brown snake (Pseudonaja textilis) (Fig. 6i); and "alpha-2-macroglobulin family Nterminal region" (Fig. 6i) were most abundant in the gastric cirri and tentacle in this study, but were also expressed in the ovaries and rhopalium samples.

\section{Nematocyst structural genes}

Genes encoding putative nematocyst structural proteins were also characterized in this study. This is in line with our aim to characterize molecular components of cubozoan nematocysts and pinpoint putative regions of nematogenesis, given the current view that venom deployment in medusozoans is exclusively controlled by nematocysts. Our findings revealed that three minicollagens, key components in nematocyst capsule development [62], were abundant almost exclusively in the $A$. alata tentacle (with adjoining pedalium base) (Figs. $5 \mathrm{c}$ and $6 \mathrm{e}, \mathrm{h}$ ), with slight expression signal in all other medusa samples. All three of the minicollagen genes identified from $A$. alata possess the characteristic collagenlike domain of short repeated tripeptides of the form Gly$\mathrm{X}-\mathrm{Y}$ flanked on both sides by proline repeats by $\mathrm{N}$ - and $\mathrm{C}$ terminal cysteine rich domains (CRD). The CRDs for two of the three genes are of the regular form (CXXXCXXXCXXXCXXXCC) and thus would be classified as Group 1 minicollagens [69]. The third has a regular $\mathrm{CRD}$ at the C-terminus but a variant form at the $\mathrm{N}$ terminus that we refer to as Group 2 variant. Gene tree reconstruction of minicollagen genes for cnidarian taxa 
a

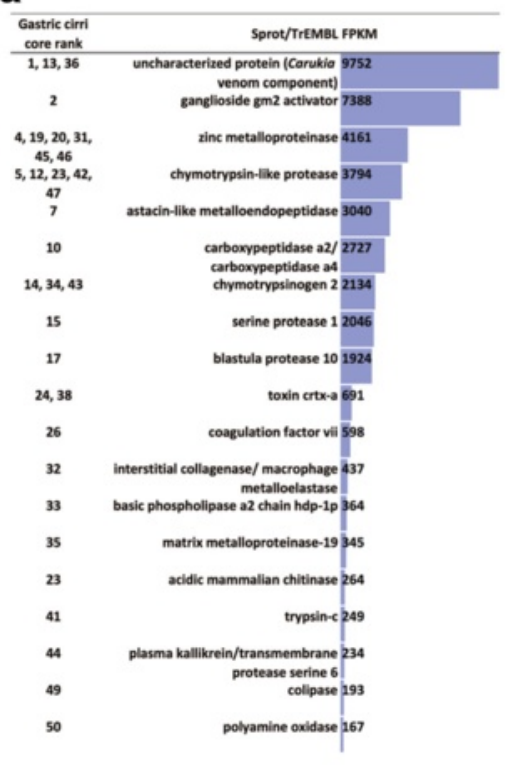

C

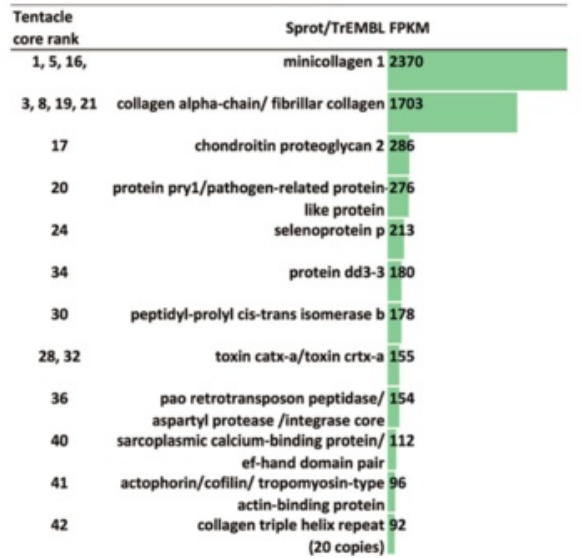

b

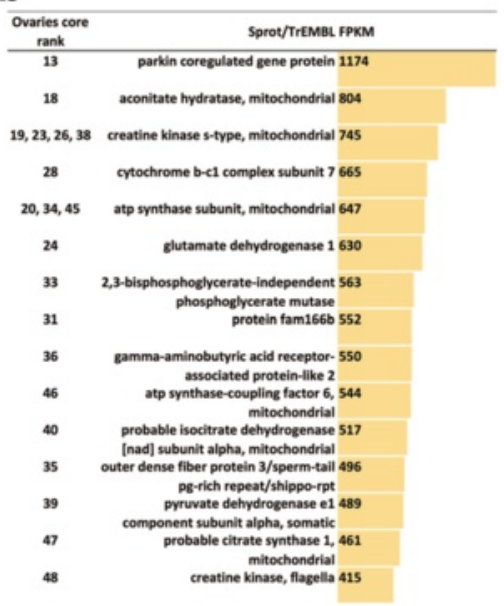

d

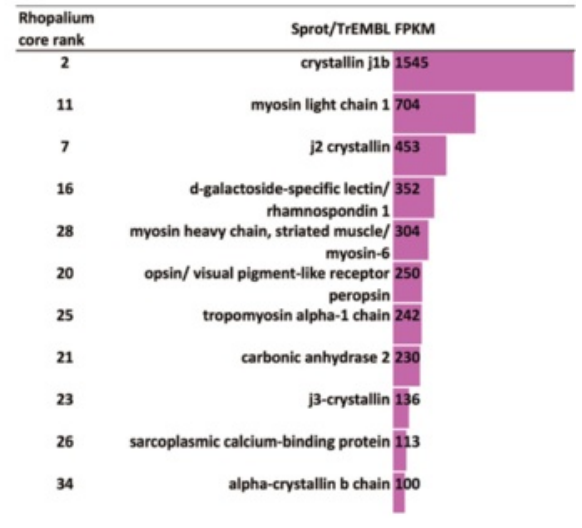

Fig. 5 a-d Abundances of annotated "core genes" in the A. alata transcriptome according to medusa sample. Column headings correspond to rank(s) among the top 50 of each core gene (or gene family) by sample according to the Venn diagram in Fig. 4b, protein annotation from UniProtKB SwissProt (Sprot) and TrEMBL (separated by a back slash) and fpkm values in a gastric cirri, b ovaries, $\mathbf{c}$ tentacle (and pedalium base), $\mathbf{d}$ rhopalium. Genes with putative functions in sperm motility are indicated with asterisks (*) in b. Genes lacking Trinotate annotations are not included. Detailed statistics (fpkm, counts, DE values for top 50 ranked genes by sample with annotations) provided in Additional file 6)

(Fig. 10) show that the minicollagens identified for A. alata cluster primarily with other Group 1 minicollagens. Of the additional nematogenesis related genes $[17,61,62$, 70-74] expressed in this study, most were almost exclusively abundant in the tentacle (with adjoining pedalium base). They include "nematocyst outer wall antigen" (NOWA) (Fig. 6e), "chondroitin proteoglycan 2" (Fig. 6f), "nematoblast-specific protein nb035-sv2/ nb035-sv3/nb012a" (Fig. 6e, f), "nematogalectin-related protein" (Fig. 6e), and "Dickkopf-related protein 3" (Fig. 6e, f, h). Five different "Dickkopf-related protein 3 " homologs were abundant in A. alata tentacle sample; with only two having notable expression in other body parts (gastric cirri, ovaries or rhopalium).

Putative vision implicated genes Here we highlight our findings of the 97 transcripts we broadly refer to as "vision implicated genes" based on preliminary candidate gene profiling (above). This effort focused specifically on genes expressed in the rhopalium of A. alata, which bears a pair of lens eyes with cornea and retina, two pairs of simple ocelli-comprising photoreceptors, and a statocyst (Fig. 1f). By comparing the rhopalium with its visual capabilities and planulae with its known eye-spot 

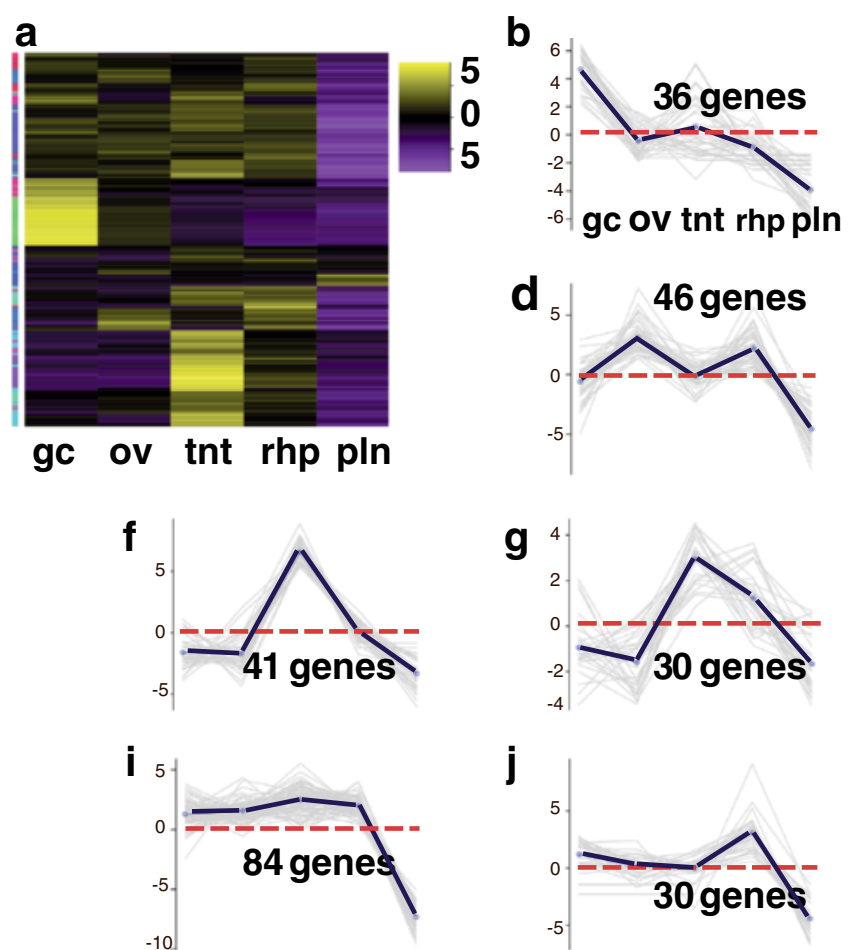

g

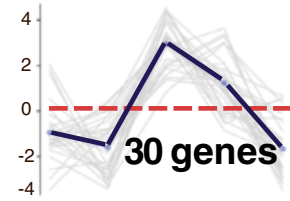

j

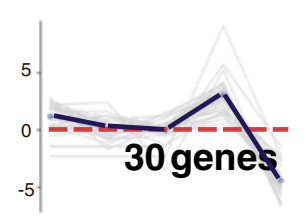

C
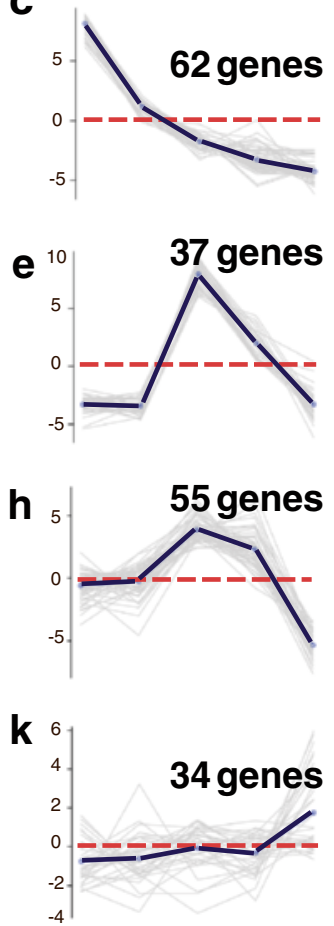

Fig. 6 a-k Venom Heatmap for A. alata. Hierarchical clustering (EdgeR) and corresponding ten subcluster profiles for the 455 genes implicated in venom differentially expressed across A. alata medusa (gastric cirri, ovaries, tentacle (with pedalium base), rhopalium) and planulae samples. Intensity of color indicates expression levels for each of the ten hierarchical clusters (vertical access). Bright yellow patches correspond to the highest peaks for each k-mean subcluster profile. K-mean profiles (b-k) match the order of column names in a, representing the mean expression of gene clusters highly abundant in each sample (centroid demarcated by the solid line; zero indicated by the horizontal dashed red line). Two bright yellow transcript clusters in the gastric cirri column correspond to peaks in plots $\mathbf{b}$ and $\mathbf{c}$; one cluster in the ovaries column corresponds to plot $\mathbf{d}$; four clusters in the tentacle column correspond to plots $\mathbf{e}, \mathbf{f}, \mathbf{g}$ and $\mathbf{h}$; one cluster in the rhopalium corresponds to plot $\mathbf{j}$ and to the less prominent peak seen in plot $\mathbf{i}$; one cluster in the planulae column corresponds to plot $\mathbf{k}$. The vertical colored bar on the left of the heatmap (a) indicates distinct patterns corresponding to the ten subcluster profiles ( $\mathrm{sc}=$ subcluster number), for which the number of genes each comprises is indicated. Abbreviations: $\mathrm{gc}=$ gastric cirri, ov = ovaries, $\mathrm{tnt}=$ tentacle (and pedalium base), $\mathrm{rhp}=$ rhopalium, and pln = planulae. Gene annotations by subcluster provided in Additional file 7

photoreceptors, against the medusa samples that lack known photoreceptors (gastric cirri, ovaries and tentacle), our aim was to identify the expression of opsins and other vision implicated genes in the rhopalium of $A$. alata, as well as in putative extraocular photoreceptors in A. alata. Hierarchical gene cluster profiling (Fig. 7ak) revealed that most of the 97 putative vision implicated genes (see "gene-profiling" above) were abundant in the rhopalium (Fig. 5d), but in many cases they were more highly expressed in other samples, in particular in medusa samples (Fig. 7c, e-j; Additional file 8).

\section{Opsins}

In this study the Trinotate report corresponding to the $A$. alata transcriptome contained a total of 41 transcripts with PFAM annotations corresponding to homologs of the " 7 transmembrane receptor (rhodopsin family)". Of the rhodopsin family, opsins are considered universal light sensitive proteins associated with photoreceptor cells of animal retinas. We found eleven opsin homologs to be variably expressed across $A$. alata medusa samples, with only six homologs most abundant in the rhopalium (Figs. 6g, h and $7 \mathrm{i}, \mathrm{h})$. A gene tree reconstruction of all rhodopsin family cnidarian genes (Fig. 11), which we rooted on the group that includes all previously known medusozoan opsins, recovered two of the three previously identified cnidarian opsin groups [30]. Group A includes only anthozoan taxa, while Group B includes all opsins previously known from medusozoans, eleven transcripts from Alatina and a few from anthozoans. However, cnidarian opsins previously identified as Group C fell into two groups-one of which includes thirty $A$. alata transcripts. This appears to be the first example of medusozoan opsins outside group B cnidarian opsins.

Among the top 10 most abundant genes in the rhopalium of A. alata was a homolog of the cubozoan lens-eye opsin for Carybdea rastonii (=C. brevipedalia) (Figs. $5 \mathrm{~d}$ and $7 \mathrm{i}$ ). The Carybdea lens eye opsin was also highly expressed in 
a
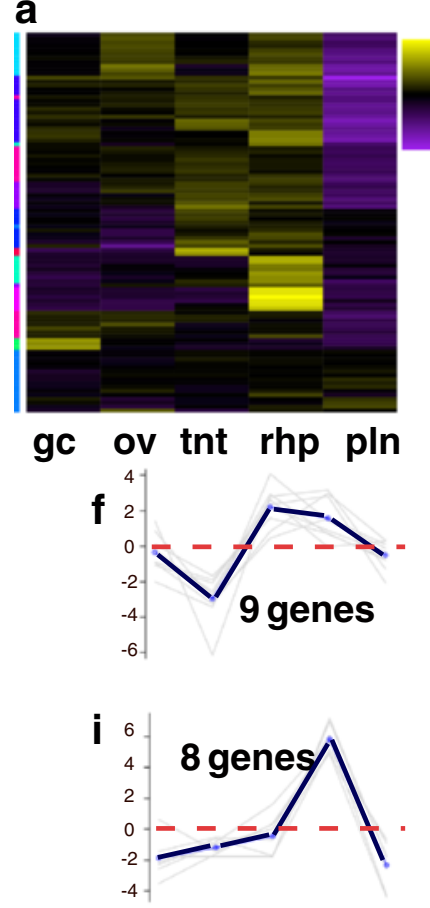

b

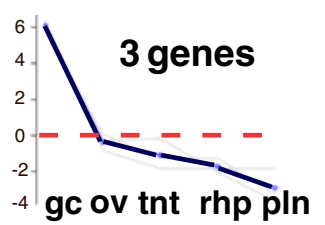

d

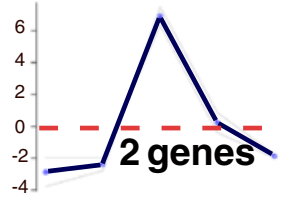

g
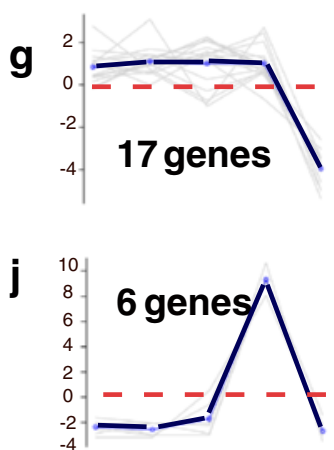

C

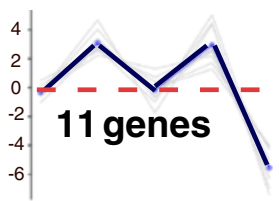

e

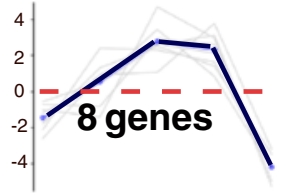

h
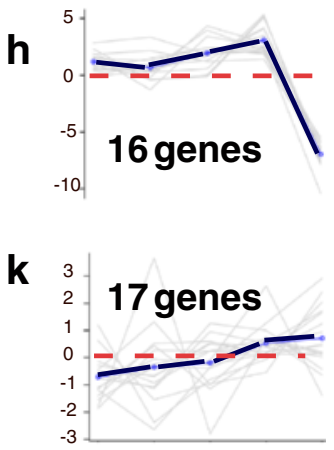

Fig. 7 a-k Vision Heatmap for A. alata. Hierarchical clustering (EdgeR) and corresponding ten subcluster profiles for the 97 genes implicated in vision and the phototransduction pathway differentially expressed across A. alata medusa (gastric cirri, ovaries, tentacle (with pedalium base), rhopalium) and planulae samples. Intensity of color indicates expression levels for each of the ten hierarchical clusters (vertical access). Bright yellow patches correspond to the highest peaks for each k-mean subcluster profile. K-mean profiles (b-k) match the order of column names in $\mathbf{a}$, representing the mean expression of gene clusters highly abundant in each sample (centroid demarcated by the solid line; zero indicated by the horizontal dashed red line). One bright yellow transcript clusters in the gastric cirri column correspond to a peak in plot $\mathbf{b}$; one cluster in the ovaries column corresponds to plot $\mathbf{c}$; three clusters in the tentacle column correspond to plots $\mathbf{d}$, e and $\mathbf{f}$; three bright yellow clusters in the rhopalium column correspond to peaks in plots $\mathbf{h}, \mathbf{i}$ and $\mathbf{j}$, and two less intense clusters correspond to peaks in plots $\mathbf{g}$ and $\mathbf{k}$, and a slightly intense yellow gene cluster in the planulae column corresponds to the peak in plot $\mathbf{k}$. The vertical colored bar on the left of the heatmap (a) indicates distinct patterns corresponding to the ten subcluster profiles ( $\mathrm{sc}=$ subcluster number), for which the number of genes each comprises is indicated. Abbreviations: $\mathrm{gc}=$ gastric cirri, ov $=\mathrm{ovaries,} \mathrm{tht=tentacle}$ (and pedalium base), rhp = rhopalium, and pln = planulae. Gene annotations by subcluster provided in Additional file 8

all $A$. alata samples, including planulae which have eye spots (Fig. 1h). Normalized counts revealed three additional opsin genes that were not differentially expressed across all samples, were almost exclusively found in the planulae sample (Fig. 11). Only two A. alata putative rhodopsin family homologs were expressed almost exclusively in the rhopalium (Trinotate top BLAST hits: "dopamine receptor 2" and "visual pigment-like receptor peropsin") (Fig. 11). Among the putative "rhodopsin family" genes expressed in medusa samples, including those annotated in the Trinotate report as non-opsin based photoreceptors, were: "compound eye opsin bcrh1/d(1b) dopamine receptor" (Fig. 7e) and "opsin rh1/mu-type opioid receptor" (Fig. 7h), "blue-sensitive opsin" (Fig. 7k), "visual pigment-like receptor peropsin" (Fig. 7d), "melanopsin-b" (Figs. 7b and 8b; Additional files 8 and 9).

\section{Chromophores}

We found that several isozymes of cis-retinol dehydrogenase, members of the retinoic acid signaling pathway, which convert retinol to retinal (Vitamin A), were expressed in the rhopalium, and in other samples including planulae (Fig. 7c, g, k). In animals, retinal (i.e., 11-cis-retinal) is bound to opsin on the photoreceptors of the retina [35], and is thought to be a universal chromophore (light-activated pigment), though various chromophores are used across Metazoa [35]. Carotenoid oxygenase beta, betacarotene 15,15'-monooxygenase (BCDO1) (Fig. 7g, h) and beta, beta-carotene 9',10'-oxygenase (BCDO2), known to irreversibly cleave carotenoids to produce the essential visual pigments retinal and retinoic acid respectively [75], were expressed in the four A. alata medusa samples (Fig. 7e), suggesting that the catalytic components are present to make retinal. We also report the expression of a putative blue-sensitive photoreceptor protein and circadian clock regulator "cryptochrome-1" in the rhopalium, but with high expression in the gastric cirri (Fig. 8b). This suggests the presence of an additional putative chromophore in A. alata that functions in extraocular blue-light mediated behaviors (e.g., 


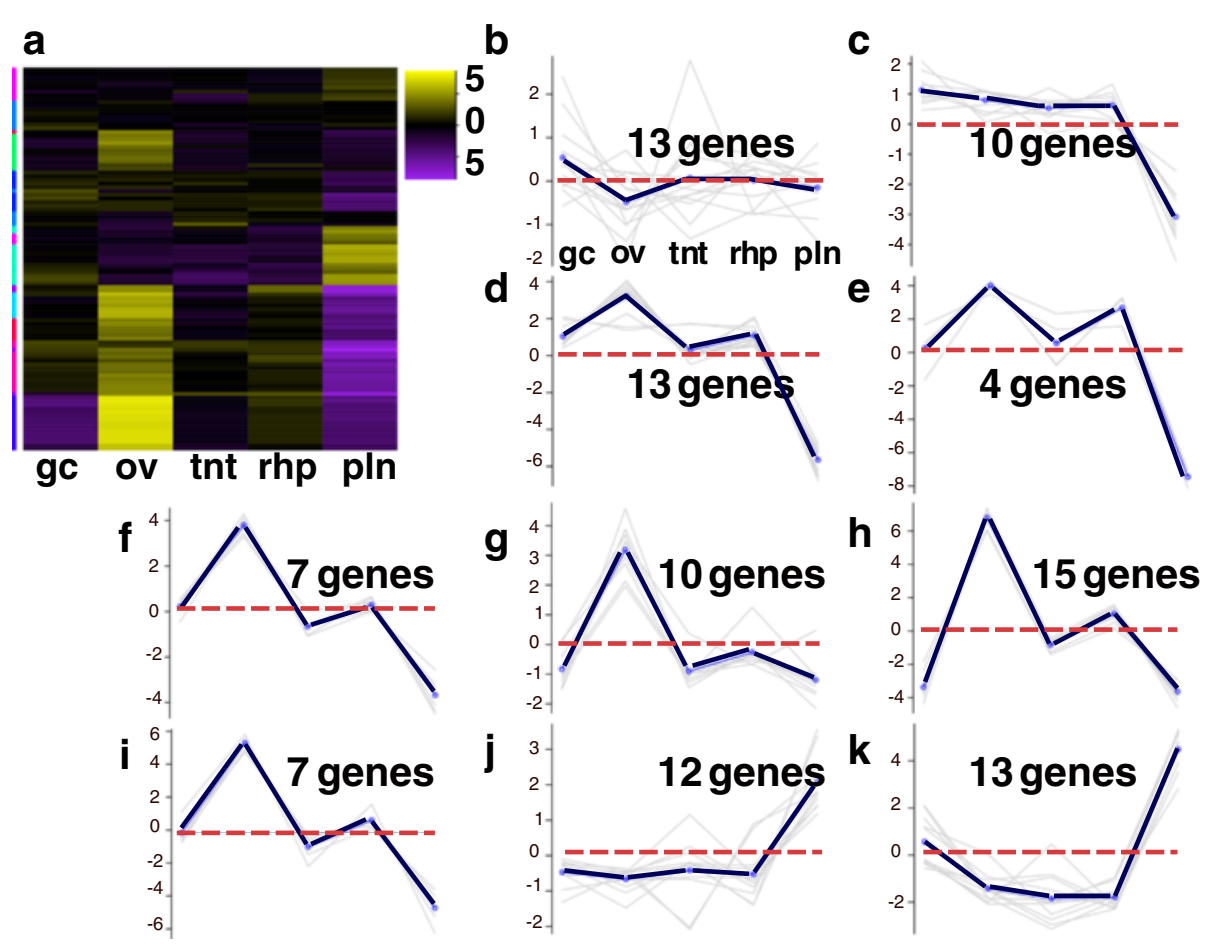

Fig. 8 a-k Sex Heatmap for A. alata. Hierarchical clustering (EdgeR) and corresponding ten subcluster profiles for the 104 genes implicated in sex and early development differentially expressed across A. alata medusa (gastric cirri, ovaries, tentacle (and pedalium base), rhopalium) and planulae samples. Intensity of color indicates expression levels for each of the ten hierarchical clusters (vertical access). Bright yellow patches correspond to the highest peaks for each k-mean subcluster profile. K-mean profiles (b-k) match the order of column names in $\mathbf{a}$, representing the mean expression of gene clusters highly abundant in each sample (centroid demarcated by the solid line; zero indicated by the horizontal dashed red line). Two yellow gene clusters in the gastric cirri column correspond to peaks in plot $\mathbf{b}$ and $\mathbf{c}$; six bright yellow clusters in the ovaries column corresponds to profiles $\mathbf{d}-\mathbf{i}$; no major abundant gene clusters were detected in the tentacle column; four less intense clusters in the rhopalium column correspond to peaks in plots $\mathbf{b}, \mathbf{d}, \mathbf{e}$, and $\mathbf{h}$; two bright clusters in the planulae column correspond to peaks in the subcluster profiles $\mathbf{j}$ and $\mathbf{k}$. The vertical colored bar on the left of the heatmap (a) indicates distinct patterns corresponding to the ten subcluster profiles (sc $=$ subcluster number), for which the number of genes each comprises is indicated. Abbreviations: $\mathrm{gc}=$ gastric cirri, ov = ovaries, tht $=$ tentacle (and pedalium base), rhp $=$ rhopalium, and pln = planulae. Gene annotations by subcluster provided in Additional file 9

phototaxis), previously documented in coral and other metazoans [76-79].

\section{Crystallins}

We found transcripts showing similarity to all three known J-crystallin groups (J1, J2, J3), and all were highly expressed in the rhopalium (Figs. $5 \mathrm{~d}$ and $7 \mathrm{i}, \mathrm{j}$ ). The J2 crystallin homolog was expressed in all samples including planulae (Fig. 7i); J3 crystallin was almost exclusively expressed in the rhopalium (Fig. 7j); as were all but a single J1 crystallin homolog that was also abundant in the ovaries (Figs. $6 \mathrm{~d}$ and $7 \mathrm{j}$ ). Crystallins are water-soluble stable structural proteins that provide transparency and increase the refractive index of eye lenses, though most also have roles unrelated to lens function. Numerous types of crystallins are found across Metazoa, and many are identical (or closely related) to commonly expressed metabolic enzymes or stress proteins [63, 80, 81]. Jcrystallins are classified in three evolutionarily independent groups, J1, J2 and J3, and thus far have only been reported in cubozoans $[63,82,83]$. A study on $T$. cystophora showed that the promotors of all three Jcrystallin genes can be activated by the paired domain transcription factor $\mathrm{PaxB}$, but the promotor sites are nonhomologous among the three J-crystallin types [63]. We aligned all known cubozoan J-crystallins (J1, J2, J3) with the respective $A$. alata homologs identified in this study (Additional file 11). The resulting three alignments illustrate the similarity between $A$. alata transcripts identified in this study and homologs of the three distinct $T$. cystophora J-crystallin types. Additionally, Alpha-crystallin B chain" (vertebrate lens heat-shock proteins) (Fig. 7i) was abundant in the rhopalium, but expressed in all five samples. Conversely, we report transcripts annotated as Stype crystallin (cephalopod lens protein) variably expressed across samples: S-crystallin 2 abundant in the rhopalium and absent in ovaries (Fig. 7f), S-crystallin 3 abundant almost exclusively in the tentacle (Fig. 7d), and $\mathrm{S}$-crystallin 4 most highly expressed in planulae and gastric cirri (Fig. 7k). 


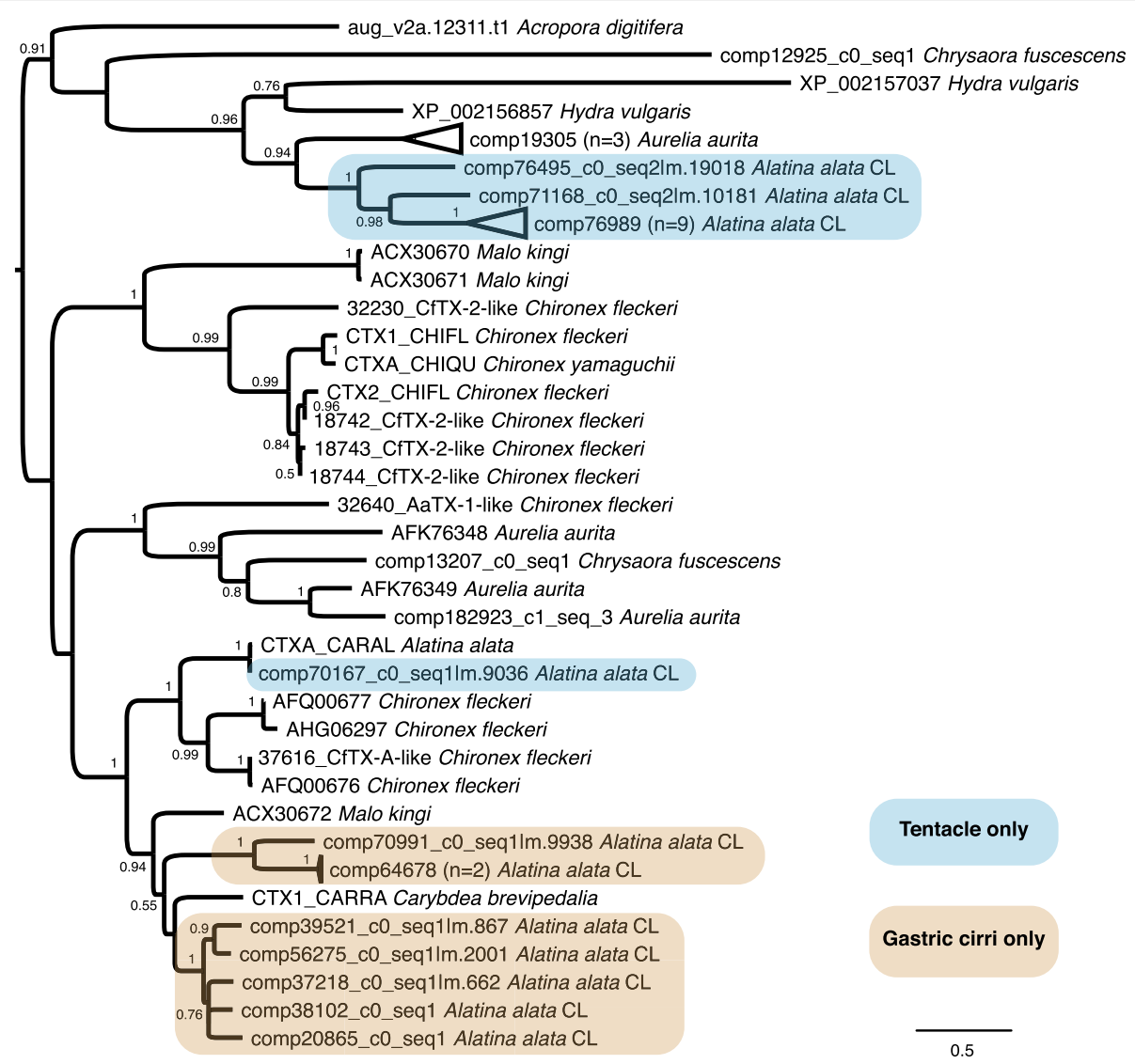

Fig. 9 Cnidarian CaTX/CrTX toxin family gene tree. ML topology of all known homologs of the CaTX/CrTX toxin family in cnidarian taxa from NCBI Genbank and transcriptome components of A. alata in this study. Assumes the WAG + G + F model of amino acid evolution, as specified as most appropriate by ProtTest v. 3.2. Shimodaira-Hasegawa-like branch support indices are shown at each node. Tissue-specific expression patterns correspond to transcripts primarily enriched in the tentacle (in blue) and gastric cirri (in beige). In A. alata, the expression of genes annotated as the CaTX-A homolog is specific to the tentacle (and pedalium base) sample (comp70167, comp71168), while genes annotated as the CrTX-A homolog are specific to gastric cirri and a single tentacle gene (comp76495). Additionally, the expression of a single gene (comp76989) annotated as both CrTX and CaTX is tentacle specific

\section{Homeobox genes and transcription factors}

Expression of putative homeobox proteins "Six $1 b$ " and "Six4" and the "Six" transcriptional co-activator "eyes absent" (Eya) homolog occurred in all A. alata medusa samples, with the highest expression in the gastric cirri. Across Metazoa, the Six-Eya complex functions downstream from certain Pax homeobox genes in a diversity of developmental processes including early eye development [84]. The putative "retinal homeobox proteins rx1b" and "rx3" were expressed in all samples, except for in the ovaries in the case of "rx1b". Retinal homeobox proteins ("rax" or retina and anterior neural fold homeobox) are essential for early eye-development and in regulation of stem cell proliferation in vertebrates [85], but have not previously been reported in cnidarians.

Putative sex and development implicated genes Here we highlight our findings of the 104 transcripts we broadly refer to as "sex implicated genes" based on preliminary candidate gene profiling (above). This effort focused mainly on genes expressed in the ovaries of $A$. alata during ovulation and internal fertilization. By definition, the ovaries are the site of oogenesis, and are situated within the gastrovascular cavity in A. alata [2]. Microscopic examination of the gastrovascular cavity of the female $A$. alata medusa in this study revealed ovulation (Fig. 1c) and internal fertilization (Fig. 1d) occurring within this cavity. By comparing our ovaries sample, which also contained zygotes and embryos, with other body parts predicted to lack reproductive material (gastric cirri, tentacle, rhopalium, and planulae), our aim was to identify genes involved in gametogenesis as well as to determine more precisely the location of internal fertilization within A. alata, which we expected would occur adjacent to the ovaries, in the sperm-saturated gastrovascular cavity [2]). Hierarchical gene cluster profiling (Fig. 8a-k) revealed that the highest expression of the 104 putative sex and developmental genes (see "gene-profiling" above) 


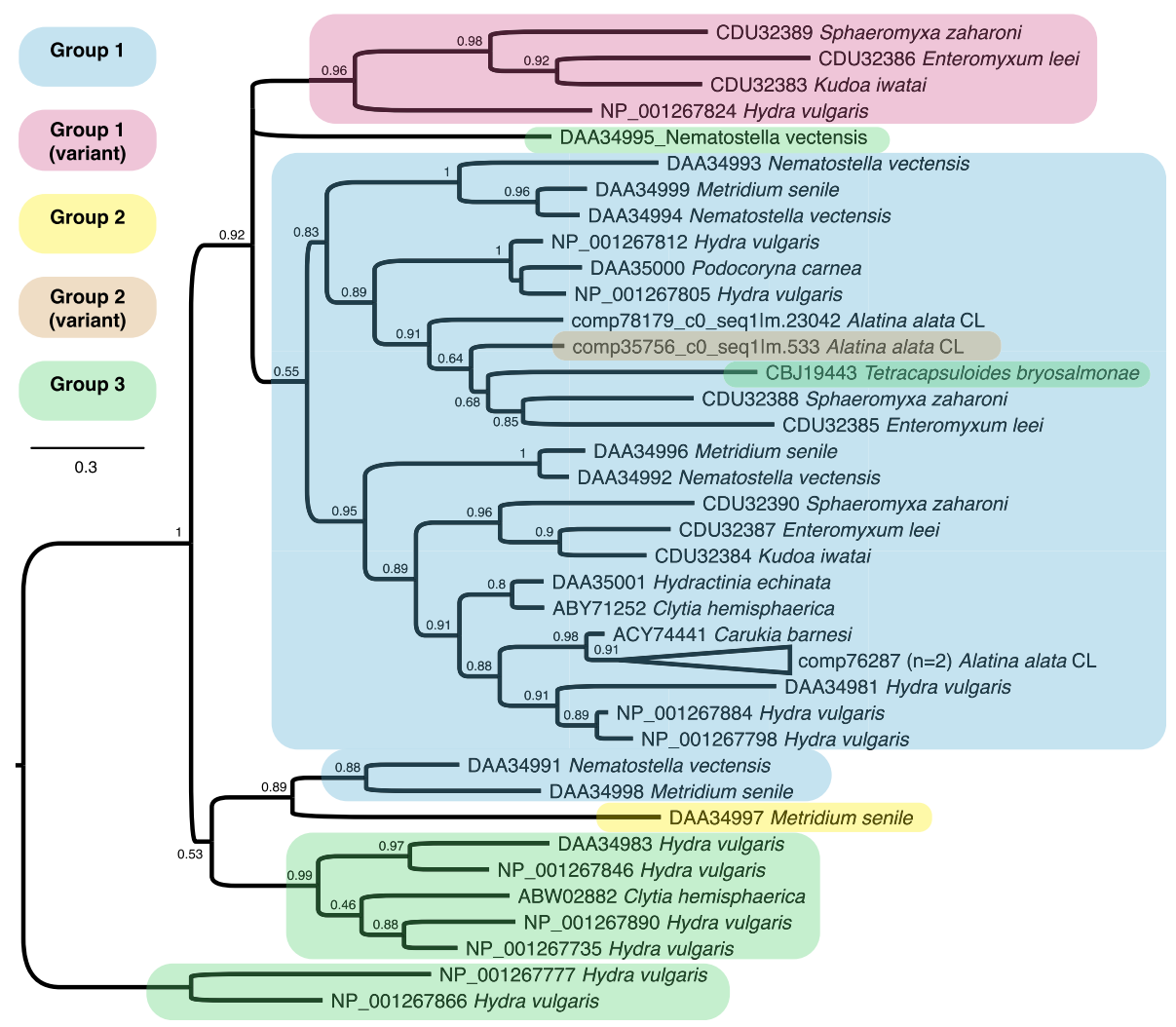

Fig. 10 Cnidarian minicollagen gene tree. ML topology of minicollagen gene family in cnidarian taxa from NCBI Genbank and transcriptome components of A. alata in this study. Assumes the BLOSS62I-G-F model of amino acid evolution, as specified as most appropriate by ProtTest v. 3.2. Shimodaira-Hasegawa-like branch support indices are shown at each node. All A. alata minicollagen types were more closely related to non-cubozoan homologs. Following Shpirer et al. 2014, Group 1 minicollagens possess N- and C-terminal cysteine rich domains (CRDs) of a regular form (CXXXCXXXCXXXCXXXCC). We use the label Group 1 (variant) to identify those minicollagens having three or more regular CRDs. Group 2 minicollagens possess one regular and one irregular CRD, with the variant form having the regular CRD at the C-terminus, whereas Group 3 minicollagens possess irregular CRDs at both termini. One (comp76287_c0) of the three recovered minicollagen homologs from A. alata was expressed across all five samples, but most abundant in the tentacle (and pedalium base)

occurred in the ovaries (Fig. 8d-i), but that many were also expressed across all samples (Additional file 9).

\section{Oogenesis and embryogenesis}

We found that homologs for the putative large lipid transfer protein Vitellogenin-2 were most abundant in A. alata ovaries (Figs. 6i and 8e), though highly expressed in all medusa samples. Conversely, genes annotated as Vitellogenin-1 or simply Vitellogenin were expressed in all medusa samples, but most abundant in the tentacle (Fig. 6i, g). Likewise, genes annotated as Apolipophorin or Apolipoprotein B-100, the other major animal protein group involved in lipoprotein processing [86], were expressed across all medusa samples but most abundant in the tentacle (Fig. $6 \mathrm{~g}-\mathrm{i}$ ). Genes of the Vitellogenin family are responsible for lipid transfer from ovarian follicle cells to oocytes, providing nutrition during embryogenesis in bilaterians and some cnidarians [86, 87], and have a documented role as egg yolk protein precursors in the ovaries of animals, including anthozoans
[88]. Gene tree reconstruction of $A$. alata transcripts with known cnidarian Vitellogenin and Apolipophorin-like proteins (Fig. 12) confirmed their homology with other cnidarian large lipid transfer proteins.

We report the abundance of multiple creatine kinase isozymes in the ovaries (Fig. 5b), all of which were expressed to some degree in all samples including planulae (Figs. 6d and 8h). Creatine kinase activity has a documented role in oogenesis and early embryogenesis in mammals [89]. More broadly though, creatine kinase is important in cells with variable rates of energy turnover, such as muscle, neurons, photoreceptors, and primitive spermatozoa [90], which is consistent with its expression in all samples in this study.

\section{Sperm motility}

Creatine kinase isozymes have also been documented in mediating high energy phosphate transport between sperm mitochondria and sperm flagellar tail [90, 91]. 


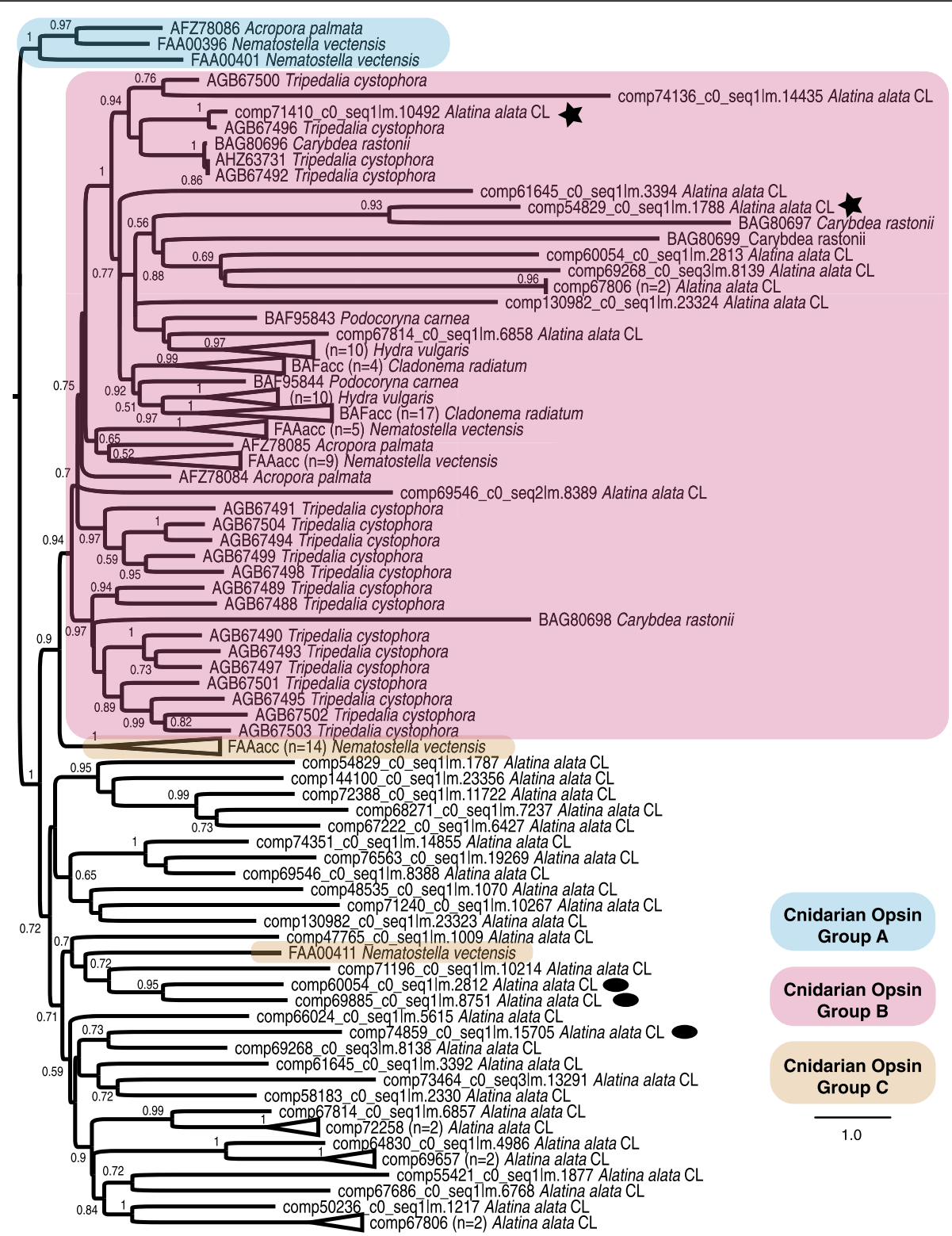

Fig. 11 Cnidarian opsin gene tree. ML topology of all known homologs of the opsin gene family in cnidarian taxa from NCBI Genbank and transcriptome components of $A$. alata in this study. Assumes the $L G+G$ model of amino acid evolution, as specified as most appropriate by ProtTest v. 3.2. Shimodaira-Hasegawa-like branch support indices are shown at each node. Blue, pink and brown shading correspond to cnidarian opsin groups A, B and C, respectively, recognized by Feuda et al. (2012). Group A is arbitrarily chosen for rooting the topology; Group B is monophyletic, but Group C cannot be given our derived topology. Stars denote opsin transcripts almost exclusively abundant in the A. alata rhopalium sample (comp54829, comp71410) and ovals denote the same in the planulae sample (comp60054, comp69885, comp74859)

Among the most abundant genes in the ovaries (Fig. 5b) were homologs functioning in sperm tail development and motility: "parkin coregulated gene protein homolog" (Fig. 8i), "outer dense fiber protein $3 /$ sperm-tail pg-rich repeat/shippo-rpt" (Fig. 8h), and multiple putative creatine kinase isoenzymes including "testis isozyme/protoflagellar creatine kinase" (Fig. 8j, h). Likewise multiple putative "serine/threonine-protein kinase" isoenzymes including "testis-specific serine/threonine-protein kinase 1" (Fig. 8g, h) were primarily abundant in the ovaries, but also variably expressed in all five samples. Expression in all samples of these sperm-related genes is consistent with the presence of ubiquitous sperm documented within the female gastrovascular cavity (where the ovaries are located) facilitating internal fertilization in this study (Fig. 1d). Sperm were also abundant in the surrounding seawater, and were undoubtedly adhered to 
the tentacles and exterior of the medusa bell when all tissue samples were excised from A. alata.

\section{Sperm capacitation}

We report the exclusive upregulation in the ovaries of the putative sperm hyperactivation and acrosomal vesicle reaction promotor protein "cation channel sperm-associated protein" (CatSper2) (Fig. 8g). CatSper genes belong to the family of voltage-gated $\mathrm{Ca}^{2+}$ channels that are crucial for sperm fertility in mammals [92]. In particular, capacitation, which typically occurs within the female reproductive tract, involves the destabilization of the acrosomal sperm head membrane allowing greater binding between sperm and oocyte during fertilization due to an increased permeability of $\mathrm{Ca}^{2+}$ [92]. Recent studies have showed that sperm of several invertebrate species also undergo capacitation (for a review see [59]). However, until now the possibility of capacitation occurring in sperm of nonbilaterian invertebrates has not been investigated. Unexpectedly, the "CUB and zona pellucida-like domaincontaining protein" was most highly abundant in the tentacle and gastric cirri (Fig. 6h, j), despite one of its known roles in ova of attracting sperm to eggs for fertilization in mammals [93]. However, the CUB and zona pellucida-like domain-containing protein is also associated with trypsinogen activation and was previously found in box jellyfish tentacles [5]. Overall, the abundance of transcripts related to sperm dynamics identified in the A. alata transcriptome permitted unforeseen profiling of molecular components involved in putative sperm capacitation and fertilization for the first time in a cubozoan.

\section{Discussion}

This study has generated the first annotated transcriptome from multiple tissues of the cubozoan Alatina alata, focusing on both the adult (medusa) and larvae (planulae). Our transcriptome significantly adds to the genomic resources available for this emerging cubozoan model. This transcriptome, based primarily on multiple adult body tissues, complements a recently published transcriptome for the same species primarily from early developmental stages [94]. Furthermore, in this study we annotated a large set of genes, allowing for an initial characterization of the molecular complexity of this cubozoan. We also compared transcript abundance across samples to identify genes putatively involved in several key features of cubozoans, namely nematogenesis and venom production, vision and sensory perception, and sexual reproduction. These quantitative data should be considered preliminary, due to lack of replication, but they are suggestive of interesting candidate genes that will be useful for future study. Below we highlight some of the major findings from this initial comparison across samples focusing specifically on genes relevant to i) prey capture and defense, ii) vision and the phototransduction pathway and iii) sexual reproduction and embryogenesis.

\section{Prey capture and defense}

In cubozoans, and more broadly in all cnidarians, prey capture and defense are based on nematocyst (stinging organelles) and associated venom. By comparing a body part abundant in penetrant nematocysts (tentacle and adjoining pedalium base) with one lacking nematocysts (gastric cirri) our aim was to identify putative site(s) of nematocyst development (nematogenesis) and venom production in A. alata.

We found that transcripts corresponding to a number of putative nematocyst structural proteins (minicollagens, nematogalectin, NOWA, chondroitin, and Dickkopf homologs) were abundant in the tentacle (and adjoining pedalium base). Although, putative nematogenic transcripts were detected primarily in the tentacle, some were also detected in non-tentacle medusa samples. We expect that this signal stems from the abundant adherent nematocysts covering the medusa bell. Together these findings are consistent with nematogenesis in A. alata occurring primarily, but not solely, in the region comprising the tentacle and adjacent pedalium base. Future in situ hybridization studies employing genes identified in nematogenesis in this study can help pinpoint more precisely nematogenic regions in A. alata.

Venom is a complex cocktail of bioactive compounds (e.g., protein and/or peptides called toxins, salts and neurotransmitters) secreted by one animal that is delivered to another animal by an infliction [57, 95]. Venom disrupts physiological and biochemical molecules of prey and predators, thus facilitating feeding and defense [57]. Nematocysts have long been considered the sole secretory structure for venom deployment in cnidarians [96]. However, we found preliminary evidence for venom production in the gastric cirri, where nematocsyts are lacking in mature A. alata. Futhermore, we found that the gastric cirri and tentacle express distinct groups of homologs of a major family of cnidarian venom proteins, the CaTX/CrTX toxin family $[66,67]$. This suggests that venom plays an important, and possibly different role in the gastric cirri and tentacle. Venom components likley differ between the nematocyst-bearing tentacle, with a primary role in immobilizing prey and warding off predators, and the gastri cirri, with a primary role in killing and digesting prey [13].

Based on our findings, we hypothesize that $A$. alata has gland cells that secrete toxins associated with the gastric cirri. Evidence was recently presented for toxinsecreting gland cells in the ectoderm of the sea anemone Nematostella in regions containing nematocysts as well as areas that may lack nematocysts [97, 98], but our findings represent the first putative case in a cubozoan. 


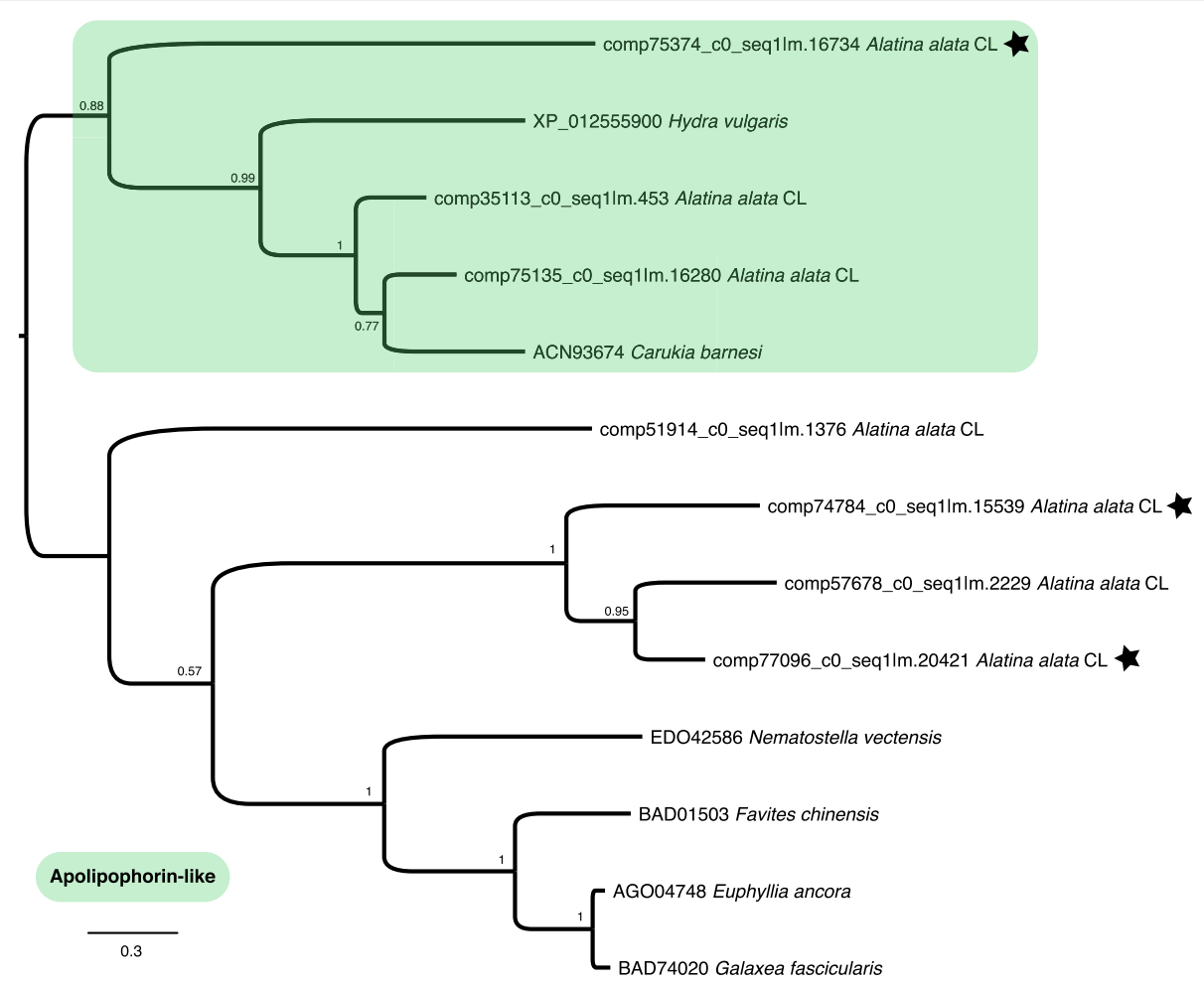

Fig. 12 Cnidarian Vitellogenin gene tree. ML topology of all known homologs of the Vitellogenin gene superfamily and apolipophorin-like putative Vitellogenin precursor in cnidarian taxa from NCBI Genbank and transcriptome components of A. alata in this study. Assumes the LG $+G$ model of amino acid evolution, as specified as most appropriate by ProtTest v. 3.2. Shimodaira-Hasegawa-like branch support indices are shown at each node. Grey (top) highlights a clade of apolipophorin-like putative Vitellogenin precursor homologs for cubozoan Carukia barnesi and A. alata from this study and hydrozoan Hydra vulgaris, while the non-highlighted clade (bottom) highlights the relationships among known Vitellogenins of cnidarian taxa. Stars designate transcripts most upregulated in the ovaries (comp74784, comp75374 \& comp77096); all others are either most highly expressed in the tentacle (comp35113 \& 51914) or equally high in the gastric cirri and tentacle samples (comp57678 \& comp75135)

Future morphological studies examining the ultrastructure of the stomach and gastric cirri, and venom gene candidate localization studies, will permit testing of the hypothesis of toxin-secreting gland cells associated with the gastric cirri of $A$. alata.

Although differences exist in the exact complement of putative bioactive toxins between the gastric cirri and tentacle sample, the venom cocktail in each body part includes transcripts from similar digestive enzyme families. A recent review of jellyfish toxins lists a number of toxin-like digestive enzymes that are deployed as components of nematocyst venom to disable homeostatic processes in prey or predators [58], as has been noted in animals possessing venom glands $[57,99,100]$. These bioactive proteins function in cytolytic, paralytic and hemolytic roles, thereby facilitating prey digestion $[58,64,101]$. Specifically we note the abundance of several enzyme groups primarily in either the tentacle or gastric cirri in A. alata that have been well studied in venomous animals [57, 99, 102, 103], namely astacinlike metalloproteinase and serine proteinase (and inhibitors), and more broadly cysteine-rich secretory proteins (CRISPs). Metalloproteinase and serine proteinase (and inhibitors) are a common component of the venom of animals with venom glands either activating toxins or acting as toxins themselves [18, 99, 100]. In particular, cysteine-rich secretory proteins identified in snake venoms are thought to inhibit smooth muscle contraction in bite victims [104]. Both metalloproteinase and CRISPs have previously been characterized in the tentacles of cubozoan $[5,105]$ and other cnidarians $[19,20,61,68,106]$. The abundance of multiple isozymes of astacin-like metalloproteinase and serine proteinase (and inhibitors) and CRISPs in the gastric cirri and tentacle of $A$. alata suggest a dual role in venom and digestion. Further studies are required to test this hypothesis given the broad involvement of these bioactive proteins in other biological processes $[5,103]$.

\section{Vision and the phototransduction pathway}

Cubozoans are the earliest diverging animal clade to have image-forming lens eyes, which are part of specialized sensory organs called rhopalia. By comparing a medusa 
body part bearing conspicuous eyes (the rhopalium) and planulae with eye spots (rhabdomeric photoreceptors) against the medusa samples that lack documented photoreceptors (gastric cirri, ovaries and tentacle), our aim was to profile the molecular components of the opsinregulated phototransduction pathway and identify additional regions of putative extraocular sensory perception in A. alata.

We found that many genes with conserved roles in vision (opsins and crystallins) were abundant in the rhopalium. Although transcripts with putative roles in lightmediated phototransduction pathway were detected primarily in the rhopalium where eyes are present, their expression was broadly detected across the medusa samples, and in some cases in planulae. We expect this signal stems from the presence of additional photoreceptors (yet undescribed) throughout the body of this cubozoan. Together these findings are consistent with a vision-related role for opsins and crystallins in the lenseye of the rhopalium, as well as a role in putative photoreceptors within non-rhopalium tissues and in planulae eye spots.

The animal phototransduction pathway is mediated by photopigments in photoreceptors consisting of two parts: a membrane protein (apoprotein) "opsin" and a chromophore "retinal" (vitamin A derivative) [107]. Opsins mediate light as phototypical G protein-coupled receptors in both visual and non-visual systems [108]. Currently more than 1000 types of opsin are known across Metazoa, with three subfamilies recognized in bilaterians: rhabdomeric (r-opsins), Go-coupled plus retinochrome retinal G protein-coupled receptor (Go/RGR) and ciliary (c-opsins) [107]. Studies characterizing opsins in cnidarians have raised the possibility that cnidarian opsins form a monophyletic clade referred to as "cnidops" that is sister to the c-opsins $[26-28,109,110]$. Other metazoan-wide analyses of opsins have categorized cnidarian opsins into three groups, A, B and C, in which each of these cnidarians opsin groups has been found, albeit with limited support, to be sister to each of the respective bilaterian opsin groups [30]. One study has revealed support for r-opsins in cnidarians [111], which is consistent with the identification of planulae eye spots as rhabdomeric photoreceptors $[24,25]$. Although a consensus is lacking on the relationships between cnidarian opsins and other metazoan opsins, our study identified a number of transcripts with molecular characters corresponding to diverse metazoan opsins (rhodopsin family) in A. alata, adding to the known diversity of this gene family within cnidarians.

Our opsin gene tree only included the known cnidarian opsins and thus does not address the question of cnidarian opsin monophyly. However, our analysis recovered homologs within two of the three previously identified cnidarian opsin groups, namely group A and B [30]. Our analysis also recovered many opsin homologs within a large group that also contains cnidarian opsin group $\mathrm{C}$, previously thought to only be present in anthozoans. The presence of this opsin group in both anthozoans and medusozoans suggests that it was present in the cnidarian ancestor.

We found several opsin genes in A. alata to be highly expressed in samples other than the rhopalium, and similar results have been reported for opsins in another cubozoan, T. cystophora [27, 28]. Based on these findings we hypothesize that cubozoans have opsin-mediated extraocular photoreception activity possibly related to phototaxis, circadian rhythm or light-mediated spawning, such as has been demonstrated in other animals, including anthozoans $[29,35,76,112]$. These findings are also suggestive of extraocular photosensitivity [25, 108, $110,113]$ that has a documented role in rhythmic behaviors and physiological processes in vertebrates and invertebrates, including nematocyst firing in cnidarians $[28,30,32,110,111,113]$. Such suggested extraocular photoreceptor cells may also comprise anatomically dispersed light sensitive neurons, in addition to ciliary or rhabdomeric morphotypes, possibly functioning in dispersed photoreception, also called the "dermal light sense" (for a review see [114]). Future characterization of the absorbance spectra for different opsin types in cubozoans, and visualization of the precise locality of expression using in situ hybridization, will help elucidate their potential functions in different medusa body parts and planulae.

In this study the expression of some of the components of the retinal photoisomerization pathway in all samples including planulae suggests that $A$. alata metabolizes the universal chromophore retinal $[35,107]$. However, transcripts for a putative blue-sensitive photoreceptor protein and circadian clock regulator cryptochrome homolog suggest an additional putative chromophore in A. alata that might function in non-rhopalium related blue-light mediated processes (e.g., phototaxis); such a function has previously been documented in other metazoans [35, 76]. Determining the precise chromophore utilized by $A$. alata must await future functional studies.

Crystallins are multifunctional proteins often related to stress or metabolic enzymes that serve as important lens components controlling optical properties [115]. The dual role crystallins play in eye lens as well as noneye related tissues is known as "gene sharing" [80]. We found that all three types of J-crystallins previously reported in T. cystophora [115] were present in A. alata and that these were typically most highly expressed in the rhopalium, with J2 crystallins showing more variable expression across samples.

We also identified transcripts corresponding to the developmental transcription factors Six and eyes absent 
(Eya), representing the first homologs of these genes identified from cubozoans. Genes in the Six-Eya homolog complex have known functions in eye development, including during embryogenesis and regeneration, in both non-bilaterians and bilaterians [79, 84, 115]. SixEya complex genes have been shown to act downstream of Pax genes [84], and PaxB expression has been reported in both adult and larval eyes of $T$. cystophora, where it is inferred to promote J-crystallin expression [28]. We also identified transcripts corresponding to the developmental transcription factors Six and eyes absent (Eya), representing the first homologs of these genes identified from cubozoans. Genes in the Six-Eya homolog complex have known functions in eye development, including during embryogenesis and regeneration, in both non-bilaterians and bilaterians [79, 84, 115]. SixEya complex genes have been shown to act downstream of Pax genes [84], and PaxB expression has been reported in both adult and larval eyes of T. cystophora, where it is inferred to promote J-crystallin expression [28]. Conversely, in the scyphozoan Aurelia, development of simple eyes is mediated by Six-Eya complex genes independent of $\operatorname{PaxB}$ expression [116]. Although the Trinotate report for the filtered $A$. alata transcriptome did not contain any transcripts annotated as PaxB, we identified two transcripts (comp95018 and comp20156) annotated as other homeobox genes that appear to be putative PaxB homologs based on sequence identity (tBLASTx) with Nematostella vectensis PaxB mRNA. Whether eye development and Six-Eya expression in $A$. alata are dependent or independent of PaxB expression remain open questions. Future studies determining the spatial localization of gene expression during eye development in A. alata may be useful for further elucidating the gene regulatory networks functioning in eye development in cubozoan rhopalia and planulae eyes spots.

\section{Sexual reproduction and embryogenesis}

Cubozoan lifecycles alternate between an asexually reproducing sessile polyp stage and a sexually reproducing motile medusa stage. By profiling the transcripts from an adult body part (ovaries) abundant in developing oocytes, our aim was to characterize the molecular components of oogenesis and early embryogenesis in A. alata. Additionally, because we found that sperm are internalized and interact with newly ovulated eggs within the gastrovascular cavity of A. alata females, our ovaries tissue sample also provided the opportunity to identify genes that might be involved in fertilization.

We identified several apparent homologs of Vitellogenin and Apolipoprotein, which have documented roles in oogenesis and embryogenesis, [86-89] and found these to be most abundant in the ovaries of A. alata. Vitellogenin is an animal egg yolk protein that is synthesized in somatic cell lineages and subsequently incorporated into developing oocytes (by receptor mediated endocytosis), eventually serving as a nutrition source during embryogenesis [86-88]. In medusozoans little is known about the characteristics of Vitellogenins as they have only been documented as egg yolk proteins in two coral species $[88,116]$ and the model sea anemone Nematostella vectensis [87]. Vitellogenin proteins are expressed in both ovarian (or putative ovaries in anthozoans, e.g., [87]) and extra-ovarian somatic cells, consistent with their important roles in processing large lipoproteins in a broad range of complex biological processes among metazoans [86], including their distinct role as honey bee venom allergens [117]. Consistent with this, we found that in A. alata, apparent homologs of Vitellogenin-2 were expressed most highly in the ovaries, yet they and other Vitellogenins and Apolipoprotein-like homologs were detected in all medusa samples. In this study we also found a number of creatine kinase genes to be most abundant in the ovaries, but many were also detected (though at much lower expression levels) in all of our samples. Creatine kinases play an important role in oogenesis and early embryogenesis in mammals [89], having a broad enzymatic function in yielding ATP by catalyzing the reversible transfer of phosphate from creatine phosphate to ADP in cells with high activity (e.g., photoreceptors, primitive-type spermatozoa) $[90,91]$.

We did not recover any genes characteristic of meiosis in the ovaries sample of $A$. alata, suggesting that the tissue was composed exclusively of mature ova at the time of sampling. It is also possible that the expression levels of putative meiosis transcripts were too low to be detected by our analyses, given our conservative transcriptome analysis protocol (see Methods). However, few studies exist that characterize the molecular aspects of sexual reproduction in cnidarians $[88,116]$, limiting the number of potential gametogenic candidate genes targeted in this study. Future transcriptome and proteome profiling studies of the gonads of A. alata and other cubozoans during medusa maturation are needed to shed light on the molecular underpinnings of the processes controlling gametogenesis in cubozoans.

In this study we also detected the expression of genes with putative roles in sperm flagella activation, proacrosomal vesicles and sperm capacitation, with many of these being most abundant in the ovaries of A alata. These morphological and biochemical changes to the sperm are necessary for the sperm to reach and fertilize an oocyte, and their occurrence has been documented within the female reproductive tract in many animals [92]. Sperm capacitation was previously thought to occur exclusively in mammals, but more recently it has been documented in several invertebrates [59]. Our study is the first to suggest that sperm capacitation 
might occur within the gastrovascular cavity (putative female reproductive tract) of a cnidarian. We note that although sperm storage structures have been reported in a single family of cubozoans (Tripedaliidae) [1, 118], we do not expect sperm storage to occur in A. alata. Morphological observations during the course of this study as well as previous studies in A. alata have identified no structure(s) with a putative role in sperm storage in either male or female medusae [2, 38, 119]. Future histological studies of $A$. alata medusae undergoing internal fertilization should elucidate the ultrastructure of the female reproductive tract and provide further insight into fertilization dynamics in this species.

Based on our observations in this and a prior study [2], monthly spermcasting aggregations of $A$. alata medusae consist entirely of males and females with mature gonad morphology. We therefore hypothesize that gonad development occurs offshore in response to environmental and molecular cues related to the lunar cycle that may instigate inshore migrations. During these monthly nearshore aggregations, which span three to four consecutive days, both sexes exhaust their entire gamete reserves in a process known as "controlled gonad rupture" [2, 120]. Male gonads completely disintegrate over the course of several hours, and females simultaneously ingest massive quantities of sperm for internal fertilization. The interaction of sperm and eggs witnessed in the gastrovascular cavity, followed by release of blastulae into the surrounding water by females within hours, along with the abundance of sperm and fertilization-related transcripts detected in the ovaries sample, corroborate previous observations [2] that fertilization occurs immediately following sperm ingestion and ovulation, adjacent to the ovaries within the gastrovascular cavity. Future molecular studies characterizing expression in sperm and eggs prior to and during fertilization will provide further insight into the dynamics of fertilization in cubozoans.

\section{Conclusions}

Whereas most cubozoans are difficult to study in their natural settings, Alatina alata is becoming a useful model for evolutionary and molecular studies because mature adults can be found predictably in near-shore waters. In this study, we generated a new genomic resource for A. alata, a transcriptome of multiple adult tissues and larvae, and characterized patterns of expression of transcripts across several body parts of a female medusa and larval planulae. We identified a large suite of candidate genes implicated in predation and defense, vision and the phototransduction pathway, and sexual reproduction and embryogenesis. This new genomic resource and the candidate genes we have identified will be valuable for further investigating the evolution of distinctive features of cubozoans, and the evolution of cnidarians more broadly.

\section{Methods \\ Specimen vouchers}

Male and female A. alata medusae were collected in Bonaire, The Netherlands. All proper collection and export permits were obtained. Medusae were kept within a glass aquarium in filtered seawater for several hours. Males shed sperm into the water that was taken up by the female manubrium. Using light microscopy (1000x) to observe the ovaries, which are located within the gastrovascular cavity, confirmation was made of ovulation and sperm and egg interaction (i.e., putative fertilization) (Fig. 1c, d). No prey items were present within the stomach and associated gastric cirri or attached to the tentacle. A live female $A$. alata medusa undergoing internal fertilization was placed on ice, and using a sterile RNasefree disposable scalpel tissue samples were quickly excised from the gastric cirri, ovaries, tentacle, rhopalium (Fig. 1). A fifth sample consisting of thousands of swimming planulae that had developed from blastulae released from different females in the lab was also collected. All samples were placed in $2 \mathrm{ml}$ cryovials and flash frozen with liquid nitrogen. Frozen samples were shipped via Cryoport to the Smithsonian Biorepository. Additionally, a single spawning $A$. alata female medusa was collected at Oil Slick Leap, Kralendijk on April 22, 2014, relaxed in $7.5 \%$ Magnesium chloride, fixed and preserved in $8 \%$ formalin, and deposited into the collection of the National Museum of Natural History, Washington, D.C. as a morphological voucher (USNM 1248604). No specific permissions were required from an ethics committee to conduct the research described herein as no humans or protected species were used.

\section{Sequencing}

The five frozen tissue samples (gastric cirri, ovaries, tentacle (and adjoining pedalium base), rhopalium, and planulae) were sequenced at the University of Kansas Medical Center-Genomics Core (KUMC), where total RNA (0.5 ug) was used for library preparation for each sample. Illumina HiSeq 2500 Sequencing System was used to generate FASTQ files, which were de-multiplexed into individual sequences for further downstream analysis.

\section{Transcriptome assembly and post-assembly analyses}

The $278 \mathrm{M}$ paired end (100 bp) raw reads from five samples were analyzed on the Smithsonian Institution High Performance Cluster, SI/HPC, and filtered using the program TrimGalore! [121] with the adaptor trimming tool Cutadapt [122] and FastQC [123] (-quality 30 -phred33 -length 25) to remove Illumina lane and 
multiplex adaptors (overlapping by $1 \mathrm{bp}$ ). ALLPATHSLG error correction software [124] was used on the $265 \mathrm{M}$ trimmed paired end reads (PAIRED_SEP option was set to 100), and unpaired reads following trimming to predict and correct sequencing errors (see [125]) and mitigate potential errors in transcriptome assemblies. All five samples (i.e., gastric cirri, ovaries, tentacle, rhopalium, and planulae) were pooled and assembled de novo into a reference transcriptome (FASTA format) for $A$. alata using Trinity (version trinityrnaseq_r20131110) [50, 51], with the following additional flags: -no_bowtie -normalize_readspath_reinforcement_distance 75 .

\section{Differential expression estimates and analyses}

RNA-Seq by Expectation Maximization (RSEM) was run on each of the five samples separately to estimate transcript abundance (read counts). A single matrix was generated corresponding to expression values for all samples as normalized Trimmed Mean of M-values (TMM) [126]. EdgeR was then used to identify differentially expressed genes in the counts matrix (-dispersion 0.1) [55]; followed by differential expression analysis to extract all genes most significantly expressed, i.e., with $p$-values $<=0.005$ and with at least a fourfold change of differential expression (-matrix iso_r123456.TMM.fpkm.matrix -P 1e-3 -C 2). This EdgeR step generated a single expression matrix of the results of all pairwise comparisons between the five samples. Further, hierarchical clustering generated a heatmap indicating clustering of similarly expressed genes (vertical axis) plotted by sample type (horizontal axis), while maintaining column order by sample (-order_columns_by_samples). This was done for all differentially expressed transcripts for all five samples (Additional file 4); just for the medusa samples (Fig. 3a); and for each of the three subsets of differentially expressed candidate genes (Figs. 6a, 7a and 8a). Color-coding on the vertical access of each heatmap indicates gene clusters with similar mean expression levels. Gene cluster patterns were further subdivided into $10 \mathrm{~K}$-mean subclusters, which were visualized as subcluster profile plots (Figs. 3b-k, 6, 7 and $8 b-k$ ). In the absence of biological replicates in this study, the specific significance of fold-change expression levels of each of the differentially expressed genes was of limited value, and we therefore chose to not further filter transcripts based on additional statistical analyses. Instead, all differentially expressed genes were targeted as candidates for narrowing our search for genes of interest by sample type. Furthermore, redoing the hierarchical clustering analysis on just the three subsets of candidate genes (putative venom, vision and sex genes) allowed us to hone in on gene clusters that were relevant to transcriptome functional annotation and profiling of $A$. alata samples types.

\section{Additional analyses}

Venn diagrams were constructed using Venny [127]. Trinotate reports for each of the three sets of candidate genes investigated in this study (venom, vision and sex) were generated by filtering the original $A$. alata Trinotate report using this custom Python script: https://github.com/ pbfrandsen/SI_scripts/blob/master/cheryl_trinotate.py.

\section{Gene tree reconstruction}

Amino acid sequences corresponding to predicted ORFs (TransDecoder), or translated nucleotide sequences, from the $A$. alata transcriptome were aligned using MUSCLE (default parameters with 5 iterations) against other cnidarian homologs from NCBI Genbank for the respective candidate genes of interest. ProtTest v. 3.2 was used to determine the most appropriate model of amino acid evolution (i.e., $\mathrm{LG}+\mathrm{G}$ or $\mathrm{WAG}+\mathrm{G}+\mathrm{F}$, or BLOSS62 I-G-F) for each alignment. ShimodairaHasegawa-like branch support indices [128] and are shown at each node of the ML topology. All ORF alignments (.nex files) predicted from TransDecoder, and the corresponding gene tree reconstructions (.tre files) are available at: https://figshare.com/articles/Supplemental_In formation_for_A_new_transcriptome_and_transcriptome_ profiling_of_adult_and_larval_tissue_in_the_box_jellyfish_ Alatina_alata_an_emerging_modelfor_studying_venom_ vision_and_sex/3471425.

\section{Additional files}

Additional file 1: Transcriptome statistics. Summary table of Trinity gene and transcript length distribution in whole transcriptome and filtered (fpkm $=1.5$ ) transcriptome. Summary table of EdgeR and Trinotate results. (XLS $34 \mathrm{~kb}$ )

Additional file 2: Trinotate report of candidate genes. A filtered Trinotate annotation report corresponding to annotations for all 651 candidate genes investigated for their putative role in venom, vision and sex (and early development) in the A. alata transcriptome. (XLS 3918 kb)

Additional file 3: Trinotate report of Cnidaria genes. A filtered Trinotate annotation report corresponding to A. alata transcripts whose top BLASTX/BLASTP hits corresponded to cnidarian genes/ proteins; summary table and pie chart included. (XLS $11650 \mathrm{~kb}$ )

Additional file 4: Heatmap and transcript DE matrix for five samples. Heatmap and corresponding matrix file used in hierarchical clustering (EdgeR) of $\sim 10 \mathrm{~K}$ transcripts differentially expressed across A. alata medusa (gastric cirri, ovaries, tentacle (with pedalium base), rhopalium) and planulae samples (columns) (of the identified $\sim 32 \mathrm{~K}$ Trinity transcripts).

(XLS $1463 \mathrm{~kb}$ )

Additional file 5: Heatmap and gene DE matrix for four medusa samples. Corresponds to Fig. 3a-k in the text. Matrix file corresponding to the heatmap showing hierarchical clustering (EdgeR) of the 2916 genes differentially expressed across A. alata medusa samples (gastric cirri, ovaries, tentacle (with pedalium base), rhopalium) (of the identified $\sim 20 \mathrm{~K}$ Trinity genes). (MATRIX $107 \mathrm{~kb}$ )

Additional file 6: Top 50 DE genes of medusa samples. Corresponds to Fig. 4b (Venn) in the text. Spreadsheet corresponding to the Venn diagram of the top fifty most highly expressed genes across the four medusa samples (from matrix in Additional file 5). Core genes are identified for each sample 
(gastric cirri, ovaries, tentacle (with pedalium base) and rhopalium). Detailed statistics (fpkm, counts, DE values for top 50 ranked genes by sample) summarized in histograms in Fig. $5 a-d$. Annotations are provided from the Trinotate report. (XLSX $66 \mathrm{~kb}$ )

Additional file 7: Venom heatmap. Corresponds to Fig. 6a-k in the text. Matrix file corresponding to matrix used for hierarchical clustering to generate the heatmap (EdgeR) of the 450 genes putative genes implicated in venom in A. alata medusa (gastric cirri, ovaries, tentacle (with pedalium base) and rhopalium) and planulae samples. Annotations are provided from the Trinotate report. (XLSX $69 \mathrm{~kb})$

Additional file 8: Vision heatmap. Corresponds to Fig. 7a-k in the text. Matrix file corresponding to matrix used for hierarchical clustering to generate the heatmap (EdgeR) of the 97 genes putative genes implicated in vision in A. alata medusa (gastric cirri, ovaries, tentacle (with pedalium base) and rhopalium) and planulae samples. Annotations are provided from the Trinotate report.

(XLSX $27 \mathrm{~kb})$

Additional file 9: Sex heatmap. Corresponds to Fig. 8a-k in the text. Matrix file corresponding to matrix used for hierarchical clustering to generate the heatmap (EdgeR) of the 104 genes putative genes implicated in sex in $A$. alata medusa (gastric cirri, ovaries, tentacle (with pedalium base) and rhopalium) and planulae samples. Annotations are provided from the Trinotate report. (XLSX $31 \mathrm{~kb}$ )

Additional file 10: Top 50 DE genes of planulae sample. Spreadsheet corresponding to the top fifty most highly expressed transcripts in the planulae sample of those differentially expressed (DE) across all five $A$. alata samples (gastric cirri, ovaries, tentacle (with pedalium base), rhopalium, planulae) (from matrix in Additional file 4). Annotations are provided from the Trinotate report. (XLSX $19 \mathrm{~kb}$ )

Additional file 11: J-Crystallins alignment. Figure corresponding to the amino acid sequence alignments of the three non-homologous cubozoan $J$-crystallins $(J 1, J 2, J 3)$. Proteins corresponding to T. cystophora J1, J2 and J3 crystallins and to C. fleckeri J3 crystallins from NCBI were aligned against the respective $\mathrm{J} 1, J 2$ and $J 3$ crystallin homolog for $A$. alata in this study. Boxes around residues indicate similarity in amino acid sequence, with black boxes corresponding to consensus regions. Sequences were aligned using MUSCLE (default parameters with 5 iterations). A. alata amino acid sequences correspond to predicted ORFs (TransDecoder), except for comp57165 which is a frame 1 translation of the Trinity transcript. (PNG $1047 \mathrm{~kb}$ )

\section{Acknowledgements}

We thank A. van Dorsten, J. van Blerk, A. Lin, R. Peachy and CIEE Bonaire staff for collection and lab assistance; S. Pirro, M. Shcheglovitova, M. Falconer, and D. Brinkman for assistance related to the study; Smithsonian Biorepository staff and Museum Support Center collections staff; KUMC Genome Core staff; Trinityrnaseq-users forum and B. Haas; Smithsonian Institution High Performance Computing Cluster and Laboratories of Analytical Biology staff: DJ Dajiang, M. Kweskin, V. Gonzalez, B. Bentlage and P. Frandsen for technical and bioinformatics support. We express our gratitude to two anonymous reviewers whose comments and suggestions helped improve the manuscript.

\section{Funding}

Funding for field work (CLA) was provided by University of Maryland Biological Sciences Eugenie Clark Scholarship and Smithsonian Peter Buck Predoctoral research grants, and for RNA-Seq by Paulyn Cartwright through NSF grant DEB-095357. JFR was supported by startup funds from the University of Florida DSP Research Strategic Initiatives \#00114464 and University of Florida Office of the Provost Programs. AGC acknowledges the Mary \& Robert Pew Public Education Fund, which supported the capture of some of the imagery in Fig. 1.

\section{Availability of data and materials}

The datasets supporting the conclusion of this article are available in the following repositories: Raw sequence data have been deposited into the NCBI Sequence Read Archive as BioProject PRJNA312373, as well as corresponding BioSamples each for gastric cirri, ovaries, tentacle, rhopalium, and planulae (SAMN4569893-SAMN 4569897). The Transcriptome Shotgun Assembly project has been deposited at DDBJ/ENA/GenBank under the accession
GEUJ00000000. The filtered A. alata transcriptome described in this paper is the first version, GEUJ01000000. Additionally, BioProject PRJNA263637 and BioSample SAMN03418513 correspond to RNA-Seq data used for a cnidarian phylogenomic study [94] that we generated from the same A. alata medusa and cohort of planulae in the current study. Additional datasets supporting the conclusions of this article are included within the article and its additional files.

\section{Authors' contributions}

PC and CLA conceived of the study. All coauthors were involved in study design and data interpretation. CLA collected A. alata medusae and planulae and generated tissue samples. PC helped to generate RNA-Seq data. CLA and JFR contributed $80 \%$ and $20 \%$ respectively to bioinformatics. AGC and CLA contributed $80 \%$ and $20 \%$ respectively to gene tree reconstruction. CLA wrote the manuscript with substantial input by AEB. All coauthors have read and contributed to the final version of the manuscript.

\section{Competing interests}

The authors declare that they have no competing interests.

Ethics approval and consent to participate

Not applicable.

\section{Author details}

'Department of Invertebrate Zoology, National Museum of Natural History, Smithsonian Institution, Washington, DC 20013, USA. ${ }^{2}$ Biological Sciences Graduate Program, University of Maryland, College Park, MD 20742, USA. ${ }^{3}$ Whitney Laboratory for Marine Bioscience, University of Florida, St Augustine, FL 32080, USA. ${ }^{4}$ Department of Biology, University of Florida, Gainesville, FL 32611, USA. ${ }^{5}$ Department of Biology, University of Maryland, College Park, MD, USA. 'Department of Ecology and Evolutionary Biology, University of Kansas, Lawrence, KS 66045, USA. ${ }^{7}$ National Systematics Laboratory, NOAA Fisheries, National Museum of Natural History, Smithsonian Institution, Washington, DC, USA.

Received: 18 May 2016 Accepted: 18 July 2016

Published online: 17 August 2016

\section{References}

1. Lewis C, Long TAF. Courtship and reproduction in Carybdea sivickisi (Cnidaria: Cubozoa). Mar. Biol. [Internet]. 2005 [cited 2014 Feb 27];147:477-83. Available from: http://link.springer.com/10.1007/s00227-005-1602-0

2. Lewis C, Bentlage B, Yanagihara AA, Gillan W, Blerk JVAN, Keil DP, et al. Redescription of Alatina alata (Reynaud, 1830) (Cnidaria: Cubozoa) from Bonaire, Dutch Caribbean. Zootaxa. 2013:3737:473-87.

3. Garm A, Lebouvier M, Tolunay D. Mating in the box jellyfish Copula sivickisiNovel function of cnidocytes. J. Morphol. [Internet]. 2015 [cited 2015 Jun 4];00. Available from: http://www.ncbi.nlm.nih.gov/pubmed/26010863

4. Lewis C, Bentlage B. Clarifying the identity of the Japanese Habu-kurage, Chironex yamaguchii, sp. nov. (Cnidaria: Cubozoa: Chirodropida). Zootaxa. 2009:65:59-65.

5. Brinkman DL, Jia X, Potriquet J, Kumar D, Dash D, Kvaskoff D, et al. Transcriptome and venom proteome of the box jellyfish Chironex fleckeri. BMC Genomics [Internet]. 2015 [cited 2015 Jun 5];16:407. Available from: http://www. biomedcentral.com/1471-2164/16/407

6. Gershwin L, Richardson AJ, Winkel KD, Fenner PJ, Lippmann J, Hore R, et al. Biology and ecology of Irukandji jellyfish (cnidaria: cubozoa). [Internet]. Adv. Mar. Biol. 2013. Available from: http://www.ncbi.nlm.nih.gov/pubmed/24182899

7. Bentlage B, Lewis C. An illustrated key and synopsis of the families and genera of carybdeid box jellyfishes (Cnidaria: Cubozoa: Carybdeida), with emphasis on the "Irukandji family" (Carukiidae). J. Nat. Hist. [Internet]. 2012; 46:2595-620. Available from: http://www.tandfonline.com/doi/abs/10.1080/ 00222933.2012 .717645

8. Nilsson D-E, Gislén L, Coates MM, Skogh C, Garm A. Advanced optics in a jellyfish eye. Nature. 2005;435:201-5.

9. Garm A, Coates MM, Gad R, Seymour J, Nilsson D-E. The lens eyes of the box jellyfish Tripedalia cystophora and Chiropsalmus sp. are slow and colorblind. J. Comp. Physiol. A. Neuroethol. Sens. Neural. Behav. Physiol. [Internet]. 2007 [cited 2014 Apr 18];193:547-57. Available from: http://www. ncbi.nlm.nih.gov/pubmed/17541674

10. Garm A, O'Connor M, Parkefelt L, Nilsson D-E. Visually guided obstacle avoidance in the box jellyfish Tripedalia cystophora and Chiropsella bronzie. J. 
Exp. Biol. [Internet]. 2007 [cited 2014 Apr 18];210:3616-23. Available from: http://www.ncbi.nlm.nih.gov/pubmed/17921163

11. O'Connor M, Garm A, Marshall JN, Hart NS, Ekström P, Skogh C, et al. Visual pigment in the lens eyes of the box jellyfish Chiropsella bronzie. Proc. Biol. Sci. [Internet]. 2010 [cited 2014 Apr 9];277:1843-8. Available from: http:// www.pubmedcentral.nih.gov/articlerender.fcgi?artid=2871879\&tool= pmcentrez\&rendertype $=$ abstract

12. Mariscal RN. Nematocysts. In: Muscatine L, Lenoff H, editors. Coelenterate Biol. Rev. new Perspect. [Internet]. New York: Academic Press; 1974 [cited 2015 Jun 5]. p. 129-78. Available from: https://www.mendeley.com/catalog/ coelenterate-biology-reviews-new-perspectives/

13. Larson RJ. Cubomedusae: Feeding functional morphology, behavior and phylogenetic position. In: Mackie GO, editor. Coelenterate Ecol. Behav. [Internet]. Boston, MA: Springer US; 1976. p. 237-45. Available from: http:// dx.doi.org/10.1007/978-1-4757-9724-4_25

14. Östman C. A guideline to nematocyst nomenclature and classification, and some notes on the systematic value of nematocysts. Sci Mar. 2000;64:31-46.

15. Gershwin L-A. Nematocysts of the Cubozoa. Zootaxa. 2006;57:1-57.

16. David CN, Challoner D. Distribution of Interstitial Cells and Differentiating Nematocytes in Nests in Hydra attenuata. Am. Zool. [Internet]. 1974;14:537-42. Available from: http://az.oxfordjournals.org/lookup/doi/10.1093/icb/14.2.537

17. Houliston E, Momose T, Manuel M. Clytia hemisphaerica: a jellyfish cousin joins the laboratory. Trends Genet. [Internet]. 2010 [cited 2011 Jul 17];26: 159-67. Available from: http://www.ncbi.n/m.nih.gov/pubmed/20227783

18. Jouiaei M, Casewell NR, Yanagihara AA, Nouwens A, Cribb BW, Whitehead D, et al. Firing the sting: chemically induced discharge of cnidae reveals novel proteins and peptides from box jellyfish (Chironex fleckeri) venom. Toxins (Basel). [Internet]. 2015 [cited 2015 Jun 5];7:936-50. Available from: http://www. pubmedcentral.nih.gov/articlerender.fcgi?artid=4379534\&tool=pmcentrez\& rendertype=abstract

19. Ponce D, Brinkman DL, Potriquet J, Mulvenna J. Tentacle Transcriptome and Venom Proteome of the Pacific Sea Nettle, Chrysaora fuscescens (Cnidaria: Scyphozoa). Toxins (Basel). [Internet]. 2016;8:102. Available from: http://www. mdpi.com/2072-6651/8/4/102

20. Weston AJ, Chung R, Dunlap WC, Morandini AC, Marques AC, Moura-da-Silva $\mathrm{AM}$, et al. Proteomic characterisation of toxins isolated from nematocysts of the South Atlantic jellyfish Olindias sambaquiensis. Toxicon [Internet]. Elsevier Ltd; 2013 [cited 2015 May 30];71:11-7. Available from: http://www.ncbi.nIm.nih. gov/pubmed/23688393

21. Li R, Yu H, Xue W, Yue Y, Liu S, Xing R, et al. Jellyfish venomics and venom gland transcriptomics analysis of Stomolophus meleagris to reveal the toxins associated with sting. J. Proteomics [Internet]. Elsevier B.V.; 2014;106:17-29. Available from: http://dx.doi.org/10.1016/j.jprot.2014.04.011

22. Conant FS. The Cubomedusae. By Franklin Story Conant. A memorial volume. Memoirs from the biological laboratory of the Johns Hopkins University, IV, 1 [Internet]. Baltimore: The Johns Hopkins Press; 1898. Available from: http:// www.biodiversitylibrary.org/item/16812\#page/9/mode/1up

23. Land MF, Nilsson D-E. Animal eyes (Oxford Animal Biology Series). USA: Oxford University Press; 2002.

24. Nordström K, Wallén, Seymour J, Nilsson D. A simple visual system without neurons in jellyfish larvae. Proc. R. Soc. London B Biol. Sci. [Internet]. 2003; 270:2349-54. Available from: http://rspb.royalsocietypublishing.org/content/ 270/1531/2349.abstract

25. Arendt D, Hausen H, Purschke G. The "division of labour" model of eye evolution. Philos. Trans. R. Soc. Lond. B. Biol. Sci. [Internet]. 2009 [cited 2014 Feb 25];364:2809-17. Available from: http://www.pubmedcentral.nih.gov/ articlerender.fcgi?artid $=2781865 \&$ tool $=$ pmcentrez\&rendertype $=$ abstract

26. Koyanagi M, Takano K, Tsukamoto H, Ohtsu K, Tokunaga F, Terakita A. Jellyfish vision starts with CAMP signaling mediated by opsin-G(s) cascade. Proc. Natl. Acad. Sci. U. S. A. [Internet]. 2008;105:15576-80. Available from: http://www.pubmedcentral.nih.gov/articlerender.fcgi?artid=2563118\&tool= pmcentrez\&rendertype $=$ abstract

27. Bielecki J, Zaharoff AK, Leung NY, Garm A, Oakley TH. Ocular and extraocular expression of opsins in the rhopalium of Tripedalia cystophora (Cnidaria: Cubozoa). PLoS One [Internet]. 2014 [cited 2015 Jan 29];9:e98870. Available from: http://www.pubmedcentral.nih.gov/articlerender.fcgi?artid=40470508 tool $=$ pmcentrez\&rendertype $=$ abstract

28. Liegertová M, Pergner J, Kozmiková I, Fabian P, Pombinho AR, Strnad H, et al. Cubozoan genome illuminates functional diversification of opsins and photoreceptor evolution. Sci. Rep. [Internet]. Nature Publishing Group; 2015;5: 11885. Available from: http://www.nature.com/doifinder/10.1038/srep11885
29. Suga H, Schmid V, Gehring WJ. Evolution and functional diversity of jellyfish opsins. Curr Biol. 2008;18:51-5.

30. Feuda R, Hamilton SC, Mcinerney JO, Pisani D. Metazoan opsin evolution reveals a simple route to animal vision. 2012;109:18868-72.

31. Schnitzler CE, Pang K, Powers ML, Reitzel AM, Ryan JF, Simmons D, et al. Genomic organization, evolution, and expression of photoprotein and opsin genes in Mnemiopsis leidyi: a new view of ctenophore photocytes. BMC Biol. [Internet]. BioMed Central Ltd; 2012;10:107. Available from: http://www. pubmedcentral.nih.gov/articlerender.fcgi?artid=3570280\&tool=pmcentrez\& rendertype $=$ abstract

32. Porter ML, Blasic JR, Bok MJ, Cameron EG, Pringle T, Cronin TW, et al. Shedding new light on opsin evolution. Proc. Biol. Sci. [Internet]. 2012 [cited 2015 Jan 1];279:3-14. Available from: http://www.pubmedcentral.nih.gov/ articlerender.fcgi?artid=3223661\&tool=pmcentrez\&rendertype $=$ abstract

33. Speiser DI, Pankey M, Zaharoff AK, Battelle B a, Bracken-Grissom HD, Breinholt JW, et al. Using phylogenetically-informed annotation (PIA) to search for light-interacting genes in transcriptomes from non-model organisms. BMC Bioinformatics [Internet]. 2014;15:350. Available from: http:// www.biomedcentral.com/1471-2105/15/350

34. Shinzato C, Shoguchi E, Kawashima T, Hamada M, Hisata K, Tanaka M, et al. Using the Acropora digitifera genome to understand coral responses to environmental change. Nature [Internet]. Nature Publishing Group; 2011 [cited 2011 Jul 25];476:320-3. Available from: http://www.nature.com/ doifinder/10.1038/nature10249

35. Mason B, Schmale M, Gibbs P, Miller MW, Wang Q, Levay K, et al. Evidence for multiple phototransduction pathways in a reef-building coral. PLoS One. 2012;7:1-9.

36. Marques AC, García J, Lewis Ames C. Internal fertilization and sperm storage in cnidarians: a response to Orr and Brennan. Trends Ecol. Evol. [lnternet]. 2015;1-2. Available from: http://linkinghub.elsevier.com/retrieve/pii/S0169534715001408

37. Garm A, Lebouvier M, Tolunay D. Mating in the box jellyfish Copula sivickisi -Novel function of cnidocytes. J. Morphol. [Internet]. 2015;00:n/a - n/a. Available from: http://doi.wiley.com/10.1002/jmor.20395

38. Gershwin L-A. Carybdea alata auct. and Manokia stiasnyi, reclassification to a new family with description of a new genus and two new species. Mem Queensl Mus. 2005;51:501-23.

39. Yanagihara AA, Kuroiwa JMY, Oliver LM, Chung JJ, Kunkel DD. Ultrastructure of a novel eurytele nematocyst of Carybdea alata Reynaud (Cubozoa, Cnidaria). Cell Tissue Res. [Internet]. 2002 [cited 2014 Apr 18];308:307-18. Available from: http://www.ncbi.nlm.nih.gov/pubmed/12037587

40. Arneson AC, Cutress CE. Life History of Carybdea alata Reynaud, 1830 (Cubomedusae). Mackie GO, editor. Coelenterate Ecol. Behav. New York: Plenum Publishing Corporation; 1976.

41. Lawley JW, Lewis Ames C, Bentlage B, Yanagihara AA, Goodwill R, Kayal E, et al. In press. The box jellyfish Alatina alata has a circumtropical distribution. Biol. Bull.

42. Morandini AC. Deep-Sea medusae (Cnidaria: Cubozoa, Hydrozoa and Scyphozoa) from the coast of Bahia (western South Atlantic, Brazil). Mitteilungen aus dem Museum für Naturkd. Berlin. Zool. Museum und Inst. für Spez. Zool. 2003;100:13-25.

43. Chiaverano LM, Holland BS, Crow GL, Blair L, Yanagihara AA. Long-term fluctuations in circalunar Beach aggregations of the box jellyfish Alatina moseri in Hawaii, with links to environmental variability. PLoS One [Internet]. 2013 [cited 2014 Feb 19];8:e77039. Available from: http:/www.pubmedcentral. nih.gov/articlerender.fcgi?artid=3806728\&tool=pmcentrez\&rendertype=abstract

44. Crow GL. Box Jellyfish (Cubozoa: Carybdeida) in Hawaiian Waters, and the First Record of Tripedalia cystophora in Hawai 'i. 2015;108:93-108.

45. Carrette T, Straehler-Pohl I, Seymour J. Early Life History of Alatina cf. moseri Populations from Australia and Hawaii with Implications for Taxonomy (Cubozoa: Carybdeida, Alatinidae). PLoS One [Internet]. 2014 [cited 2014 Jan 28];9:e84377. Available from: http://www.pubmedcentral.nih.gov/ articlerender.fcgi?artid=3893091\&tool=pmcentrez\&rendertype $=$ abstract

46. Brekhman V, Malik A, Haas B, Sher N, Lotan T. Transcriptome profiling of the dynamic life cycle of the scypohozoan jellyfish Aurelia aurita. BMC Genomics [Internet]. 2015;16. Available from: http://www.biomedcentral. com/1471-2164/16/74

47. Sanders SM, Shcheglovitova M, Cartwright P. Differential gene expression between functionally specialized polyps of the colonial hydrozoan Hydractinia symbiolongicarpus (Phylum Cnidaria). BMC Genomics [Internet]. 2014;15:406. Available from: http://www.pubmedcentral.nih.gov/ articlerender.fcgi?artid $=4072882 \&$ tool $=$ pmcentrez\&rendertype $=$ abstract 
48. Macrander J, Brugler MR, Daly M. A RNA-seq approach to identify putative toxins from acrorhagi in aggressive and non-aggressive Anthopleura elegantissima polyps. BMC Genomics [Internet]. 2015 [cited 2015 Jun 4];16: 221. Available from: http://www.pubmedcentral.nih.gov/articlerender. fcgi?artid $=4397815 \&$ tool $=$ pmcentrez\&rendertype $=$ abstract

49. Zapata F, Goetz FE, Smith S A., Howison M, Siebert S, Church SH, et al. Phylogenomic Analyses Support Traditional Relationships within Cnidaria. PLoS One [Internet]. 2015;10:e0139068. Available from: http://dx.plos.org/10. 1371/journal.pone.0139068

50. Haas BJ, Papanicolaou A, Yassour M, Grabherr M, Blood PD, Bowden J, et al. De novo transcript sequence reconstruction from RNA-seq using the Trinity platform for reference generation and analysis. Nat. Protoc. [Internet]. 2013;8:1494-512. Available from: http:/www.nature.com/doifinder/10.1038/nprot.2013.084

51. Grabherr MG, Haas BJ, Yassour M, Levin JZ, Thompson DA, Amit I, et al. Fulllength transcriptome assembly from RNA-Seq data without a reference genome. Nat. Biotechnol. [Internet]. 2011;29:644-52. Available from: https:// trinotate.github.io

52. Tatusov RL, Fedorova ND, Jackson JD, Jacobs AR, Kiryutin B, Koonin EV, et al. The COG database: an updated version includes eukaryotes. BMC Bioinformatics. 2003:4:41.

53. Parra G, Bradnam K, Korf I. CEGMA: A pipeline to accurately annotate core genes in eukaryotic genomes. Bioinformatics. 2007;23:1061-7.

54. Li B, Dewey CN. RSEM: accurate transcript quantification from RNA-Seq data with or without a reference genome. BMC Bioinformatics [Internet]. 2011 [cited 2014 Jul 10]:12:323. Available from: http://www.pubmedcentral.nih. gov/articlerender.fcgi?artid=3163565\&tool=pmcentrez\&rendertype=abstract

55. Robinson MD, McCarthy DJ, Smyth GK. edgeR: A Bioconductor package for differential expression analysis of digital gene expression data. Bioinformatics. 2010;26:139-40.

56. Chen Y, Mccarthy D, Ritchie M, Robinson M, Smyth GK. edgeR: differential expression analysis of digital gene expression data User' s Guide. 2016.

57. Casewell NR, Wüster W, Vonk FJ, Harrison R a, Fry BG. Complex cocktails: the evolutionary novelty of venoms. Trends Ecol. Evol. [Internet]. 2012 [cited 2015 Jun 4];28:219-29. Available from: http://www.ncbi.n/m.nih.gov/ pubmed/23219381

58. Jouiaei M, Yanagihara AA, Madio B, Nevalainen T, Alewood P, Fry B. Ancient Venom Systems: A Review on Cnidaria Toxins. Toxins (Basel). [Internet]. 2015;7:2251-71. Available from: http://www.mdpi.com/2072-6651/7/6/2251/

59. Aungsuchawan $\mathrm{S}$, Browdy $\mathrm{CL}$, Withyachumnarnkul B. Sperm capacitation of the shrimp Litopenaeus vannamei. Aquac Res. 2011:42:188-95.

60. Kurz EM, Holstein TW, Petri BM, Engel J, David CN. Mini-collagens in Hydra nematocytes. J Cell Biol. 1991;115:1159-69.

61. Balasubramanian PG, Beckmann A, Warnken U, Schnölzer M, Schüler A, Bornberg-Bauer E, et al. Proteome of Hydra nematocyst. J Biol Chem. 2012; 287:9672-81.

62. David CN, Ozbek S, Adamczyk P, Meier S, Pauly B, Chapman J, et al. Evolution of complex structures: minicollagens shape the cnidarian nematocyst. Trends Genet. [Internet]. 2008 [cited 2015 Jan 29];24:431-8. Available from: http://www.ncbi.nlm.nih.gov/pubmed/18676050

63. Kozmik Z, Swamynathan SK, Ruzickova J, Jonasova K, Paces V, Vlcek C, et al. Cubozoan crystallins: Evidence for convergent evolution of pax regulatory sequences. Evol Dev. 2008;10:52-61.

64. Brinkman DL, Burnell JN. Biochemical and molecular characterisation of cubozoan protein toxins. Toxicon [Internet]. Elsevier Ltd; 2009;54:1162-73. Available from: http://dx.doi.org/10.1016/j.toxicon.2009.02.006

65. Nagai H. Recent Progress in Jellyfish Toxin Study. J. Heal. Sci. [Internet]. 2003:49:337-40. Available from: http://joi.jlc.jst.go.jp/JST.JSTAGE/jhs/49. 337?from=CrossRef

66. Nagai H, Takuwa K, Nakao M, Ito E, Miyake M, Noda M, et al. Novel Proteinaceous Toxins from the Box Jellyfish (Sea Wasp) Carybdea rastoni. Biochem. Biophys. Res. Commun. [Internet]. 2000;275:582-8. Available from: http://www.sciencedirect.com/science/article/pii/S0006291X00933539

67. Nagai H, Takuwa K, Nakao M, Sakamoto B, Crow GL, Nakajima T. Isolation and Characterization of a Novel Protein Toxin from the Hawaiian Box Jellyfish (Sea Wasp) Carybdea alata. Biochem. Biophys. Res. Commun. [Internet]. 2000;275:589-94. Available from: http://www.sciencedirect.com/ science/article/pii/S0006291X00933527

68. Gacesa R, Chung R, Dunn SR, Weston AJ, Jaimes-Becerra A, Marques $A C$, et al. Gene duplications are extensive and contribute significantly to the toxic proteome of nematocysts isolated from Acropora digitifera (Cnidaria: Anthozoa: Scleractinia). BMC Genomics [Internet]. BMC
Genomics; 2015;16:774. Available from: http://www.biomedcentral.com/ 1471-2164/16/774

69. Shpirer E, Chang E, Diamant A, Rubinstein N, Cartwright P, Huchon D. Diversity and evolution of myxozoan minicollagens and nematogalectins. BMC Evol. Biol. [Internet]. 2014;14:205. Available from: http://www. biomedcentral.com/1471-2148/14/205

70. Horibata Y, Higashi H, Ito M. Transglycosylation and Reverse Hydrolysis Reactions of Endoglycoceramidase from the Jellyfish. J. Biochem. [Internet]. 2001;130:263-8. Available from: http://jb.oxfordjournals.org/content/130/2/ 263.full.pdf

71. Engel U, Ozbek S, Streitwolf-Engel R, Petri B, Lottspeich F, Holstein TW. Nowa, a novel protein with minicollagen Cys-rich domains, is involved in nematocyst formation in Hydra. J Cell Sci. 2002;115:3923-34.

72. Milde S, Hemmrich G, Anton-Erxleben F, Khalturin K, Wittlieb J, Bosch TCG. Characterization of taxonomically restricted genes in a phylum-restricted cell type. Genome Biol. 2009;10:R8.

73. Forêt S, Knack B, Houliston E, Momose T, Manuel M, Quéinnec E, et al. New tricks with old genes: The genetic bases of novel cnidarian traits. Trends Genet. 2010;26:154-8.

74. Eckert T. In silico study on sulfated and non-sulfated carbohydrate chains from proteoglycans in Cnidaria and interaction with collagen. Open J Phys Chem. 2012;02:123-33.

75. Wyss A. Functions and Actions of Retinoids and Carotenoids: Building on the Vision of James Allen Olson Carotene Oxygenases: A New Family of Double Bond Cleavage Enzymes. Am. Soc. Nutr. Sci. 2004; 246-50.

76. Rivera AS, Ozturk N, Fahey B, Plachetzki DC, Degnan BM, Sancar A, et al. Blue-light-receptive cryptochrome is expressed in a sponge eye lacking neurons and opsin. J. Exp. Biol. [Internet]. 2012;215:1278-86. Available from: http://jeb.biologists.org/cgi/doi/10.1242/jeb.067140

77. Reitzel AM, Tarrant AM, Levy O. Circadian clocks in the cnidaria: Environmental entrainment, molecular regulation, and organismal outputs. Integr Comp Biol. 2013;53:118-30.

78. Liedvogel M, Mouritsen H. Cryptochromes-a potential magnetoreceptor: what do we know and what do we want to know? J R Soc Interface. 2010;7 Suppl 2:S147-62.

79. Rivera AS, Winters I, Rued A, Ding S, Posfai D, Cieniewicz B, et al. The evolution and function of the Pax/Six regulatory network in sponges. Evol Dev. 2013;15:186-96

80. Piatigorsky J, Brient WEO, Norman BL, Kalumuckt K, Wistow GJ, Borras T, et al. Gene sharing by $\delta$-crystallin and argininosuccinate lyase. Amino Acids. 1988;85:3479-83.

81. Kozmik Z, Ruzickova J, Jonasova K, Matsumoto Y, Vopalensky P, Kozmikova I, et al. Assembly of the cnidarian camera-type eye from vertebrate-like components. Proc. Natl. Acad. Sci. U. S. A. [Internet]. 2008;105:8989-93. Available from: http://www.pubmedcentral.nih.gov/articlerender. fcgi?artid $=2449352 \&$ tool=pmcentrez\&rendertype=abstract

82. Piatigorsky J, Horwitz J, Kuwabara T, Cutress CE. The cellular eye lens and crystallins of cubomedusan jellyfish. J Comp Physiol A. 1989;164: 577-87.

83. Piatigorsky J, Horwitzs J, Norman BL. J1-crystallins of the Cubomedusan jellyfish lens constitute a novel family encoded in at least three intronless genes. J Biol Chem. 1993;2643:11894-901.

84. Kumar JP. The sine oculis homeobox (SIX) family of transcription factors as regulators of development and disease. Cell Mol Life Sci. 2009;66:565-83.

85. Furukawa T, Kozak CA, Cepko CL. rax, a novel paired-type homeobox gene, shows expression in the anterior neural fold and developing retina. Proc. Natl. Acad. Sci. [Internet]. 1997;94:3088-93. Available from: http://www.pnas.org/cgi/ doi/10.1073/pnas.94.7.3088

86. Hayward A, Takahashi T, Bendena WG, Tobe SS, Hui JHL. Comparative genomic and phylogenetic analysis of vitellogenin and other large lipid transfer proteins in metazoans. FEBS Lett. [Internet]. Federation of European Biochemical Societies; 2010;584:1273-8. Available from: http://dx.doi.org/10. 1016/j.febslet.2010.02.056

87. Levitan S, Sher N, Brekhman V, Ziv T, Lubzens E, Lotan T. The making of an embryo in a basal metazoan: Proteomic analysis in the sea anemone Nematostella vectensis. Proteomics [Internet]. 2015;15:4096-104. Available from: http://doi.wiley.com/10.1002/pmic.201500255

88. Shikina S, Chen CJ, Chung YJ, Shao ZF, Liou JY, Tseng HP, et al. Yolk formation in a stony coral Euphyllia ancora (Cnidaria, Anthozoa): Insight into the evolution of vitellogenesis in nonbilaterian animals. Endocrinology. 2013;154:3447-59. 
89. lyengar MR, lyengar CW, Chen HY, Brinster RL, Bornslaeger E, Schultz RM. Expression of creatine kinase isoenzyme during oogenesis and embryogenesis in the mouse. Dev Biol. 1983;96:263-8.

90. Pineda $A O$, Ellington WR. Structural and functional implications of the amino acid sequences of dimeric, cytoplasmic and octameric mitochondrial creatine kinases from a protostome invertebrate. Eur J Biochem. 1999;264:67-73.

91. Wallimann T, Hemmer W. Creatine kinase in non-muscle tissues and cells. Mol Cell Biochem. 1994;133-134:193-220.

92. Rahman MS, Kwon W-S, Pang M-G. Calcium Influx and Male Fertility in the Context of the Sperm Proteome: An Update. Biomed Res. Int. [Internet] 2014;2014:1-13. Available from: http://www.hindawi.com/journals/bmri/ 2014/841615/

93. Adonin LS, Shaposhnikova TG, Podgornaya O. Aurelia aurita (Cnidaria) Oocytes' contact plate structure and development. PLoS One. 2012;7:1-10.

94. Zapata F, Goetz FE, Smith SA, Howison M, Siebert S, Church S, et al. Phylogenomic analyses support traditional relationships within Cnidaria. bioRxiv beta. 2015;4-6.

95. Fry BG, Roelants K, Champagne DE, Scheib H, Tyndall JD a, King GF, et al. The toxicogenomic multiverse: convergent recruitment of proteins into animal venoms. Annu. Rev. Genomics Hum. Genet. [Internet]. 2009 [cited 2015 Mar 31];10:483-511. Available from: http://www.ncbi.nlm.nih.gov/ pubmed/19640225

96. Galliot B. Hydra, a fruitful model system for 270 years. Int J Dev Biol. 2012; 56:411-23.

97. Moran Y, Genikhovich G, Gordon D, Wienkoop S, Zenkert C, Ozbek S, et al. Neurotoxin localization to ectodermal gland cells uncovers an alternative mechanism of venom delivery in sea anemones. Proc R Soc B Biol Sci. 2012; 279:1351-8.

98. Moran Y, Praher D, Schlesinger A, Ayalon A, Tal Y, Technau U. Analysis of soluble protein contents from the nematocysts of a model sea anemone sheds light on venom evolution. Mar Biotechnol. 2013;15:329-39.

99. Junqueira-de-Azevedo ILM, Bastos CMV, Ho PL, Luna MS, Yamanouye N, Casewell NR. Venom-related transcripts from Bothrops jararaca tissues provide novel molecular insights into the production and evolution of snake venom. Mol. Biol. Evol. [Internet]. 2015;32:754-66. Available from: http://mbe.oxfordjournals.org/content/32/3/754.abstract

100. Calvete JJ, Sanz L, Angulo Y, Lomonte B, Gutiérrez JM. Venoms, venomics, antivenomics. FEBS Lett. [Internet]. Federation of European Biochemical Societies; 2009;583:1736-43. Available from: http://www.ncbi.nlm.nih.gov/ pubmed/19303875

101. Zhang M, Fishman Y, Sher D, Zlotkin E. Hydralysin, a novel animal groupselective paralytic and cytolytic protein from a noncnidocystic origin in Hydra. Biochemistry [Internet]. 2003;42:8939-44. Available from: http://www.ncbi.nlm nih.gov/pubmed/12885226

102. Trevisan-Silva D, Gremski LH, Chaim OM, da Silveira RB, Meissner GO, Mangili OC, et al. Astacin-like metalloproteases are a gene family of toxins present in the venom of different species of the brown spider (genus Loxosceles). Biochimie. 2010;92:21-32.

103. Möhrlen F, Maniura M, Plickert G, Frohme M, Frank U. Evolution of astacinlike metalloproteases in animals and their function in development. Evol Dev. 2006;8:223-31.

104. Yamazaki Y, Morita T. Structure and function of snake venom cysteine-rich secretory proteins. Toxicon. 2004:44:227-31.

105. Avila Soria G. Molecular characterization of Carukia barnesi and Malo kingi, cnidaria; Cubozoa; Carybdeidae. PhD Thesis [Internet]. James Cook University; 2009. Available from: http://eprints.jcu.edu.au/8218

106. Ponce D, Brinkman DL, Luna-Ramirez K, Wright CE, Dorantes-Aranda JJ. Comparative study of the toxic effects of Chrysaora quinquecirrha (Cnidaria: Scyphozoa) and Chironex fleckeri (Cnidaria: Cubozoa) venoms using cellbased assays. Toxicon. 2015;106:57-67.

107. Shichida Y, Matsuyama T. Evolution of opsins and phototransduction. Philos. Trans. R. Soc. Lond. B. Biol. Sci. [Internet]. 2009 [cited 2015 Jan 19];364:2881-95. Available from: http://www.pubmedcentral.nih.gov/articlerender.fcgi?artid= 2781858\&tool=pmcentrez\&rendertype $=$ abstract

108. Terakita A. Protein family review The opsins. Genome Biol. [Internet]. 2005;6: 1-9. Available from: http://genomebiology.com/2005/6/3/213

109. Plachetzki DC, Degnan BM, Oakley TH. The origins of novel protein interactions during animal opsin evolution. PLoS One [Internet]. 2007 [cited 2015 Jan 25];2:e1054. Available from: http://www.pubmedcentral.nih.gov/ articlerender.fcgi?artid=2013938\&tool=pmcentrez\&rendertype=abstract
110. Plachetzki DC, Fong CR, Oakley TH. The evolution of phototransduction from an ancestral cyclic nucleotide gated pathway. Proc. Biol. Sci. [Internet]. 2010 [cited 2011 Jun 12];277:1963-9. Available from: http://www. pubmedcentral.nih.gov/articlerender.fcgi?artid=2880087\&tool=pmcentrez\& rendertype $=$ abstract

111. Feuda R, Rota-Stabelli O, Oakley TH, Pisani D. The comb jelly opsins and the origins of animal phototransduction. Genome Biol. Evol. [Internet]. 2014 [cited 2015 Jan 29];6:1964-71. Available from: http://www.pubmedcentral.nih.gov/ articlerender.fcgi?artid=4159004\&tool=pmcentrez\&rendertype=abstract

112. Levy O, Appelbaum L, Leggat W, Gothlif Y, Hayward DC, Miller DJ, et al. Light-Responsive Cryptochromes from a Simple Multicellular Animal, the Coral Acropora millepora. Science (80-.). [Internet]. 2007;318:467-70. Available from: http://www.sciencemag.org/cgi/doi/10.1126/science.1145432

113. Plachetzki DC, Fong CR, Oakley TH. Cnidocyte discharge is regulated by light and opsin-mediated phototransduction. BMC Biol. [Internet]. BioMed Central Ltd; 2012;10:17. Available from: http://www.biomedcentral.com/ 1741-7007/10/17

114. Desmond Ramirez M, Speiser DI, Sabrina Pankey M, Oakley TH. Understanding the dermal light sense in the context of integrative photoreceptor cell biology. Vis Neurosci. 2011;28:265-79.

115. Piatigorsky J, Norman B, Dishaw LJ, Kos L, Horwitz J, Steinbach PJ, et al. J3crystallin of the jellyfish lens: similarity to saposins. Proc. Natl. Acad. Sci. U. S. A. [Internet]. 2001;98:12362-7. Available from: http://www.pubmedcentral. nih.gov/articlerender.fcgi?artid=60059\&tool=pmcentrez\&rendertype=abstrac

116. Hayakawa H, Andoh T, Watanabe T. Identification of a novel yolk protein in the hermatypic coral Galaxea fascicularis. Zoolog. Sci. [Internet]. 2007;24: 249-55. Available from: http://www.bioone.org/doi/abs/10.2108/zsj.24.249

117. Danneels E, Van Vaerenbergh M, Debyser G, Devreese B, de Graaf D. Honeybee Venom Proteome Profile of Queens and Winter Bees as Determined by a Mass Spectrometric Approach. Toxins (Basel). [Internet]. 2015;7:4468-83. Available from: http://www.mdpi.com/2072-6651/7/11/4468/

118. Straehler-Pohl I, Garm A, Morandini AC. Sexual dimorphism in Tripedaliidae (Conant 1897) (Cnidaria, Cubozoa, Carybdeida). 2014;3785:533-49.

119. Mayer AG. Medusae of the Hawaiian Islands Collected by the Steamer albatross in 1902. Bull US Fish Comm. 1906;23:1131-43.

120. Miller RL. Cnidaria. In: Adiyodi KG, Adiyodi RG, editors. Reprod. Biol. Invertebr. Vol. II Spermatogenes. Sperm Funct. John Wiley \& Sons Ltd.; 1983. p. pp. 23-73.

121. Krueger F. Trim Galore!. [Internet]. 2012. Available from: http://www. bioinformatics.babraham.ac.uk/projects/trim_galore/

122. Martin M. Cutadapt removes adapter sequences from high-throughput sequencing reads. EMBnet.journal [Internet]. 2011;17.1:10-2. Available from: http://journal.embnet.org/index.php/embnetjournal/article/view/200

123. Andrews S. FastQC. http://www.bioinformatics.babraham.ac.uk/projects/ fastqc/. 2014.

124. Gnerre S, Maccallum I, Przybylski D, Ribeiro FJ, Burton JN, Walker BJ, et al. High-quality draft assemblies of mammalian genomes from massively parallel sequence data. Proc. Natl. Acad. Sci. U. S. A. [Internet]. 2011 [cited 2014 Jul 13];108:1513-8. Available from: http://www.pubmedcentral.nih.gov/ articlerender.fcgi?artid=3029755\&tool=pmcentrez\&rendertype=abstract

125. Macmanes MD, Eisen MB. Improving transcriptome assembly through error correction of high-throughput sequence reads. Peer] [Internet]. 2013 [cited 2015 Jan 6];1:e113. Available from: http://www.pubmedcentral.nih.gov/ articlerender.fcgi?artid=3728768\&tool=pmcentrez\&rendertype=abstract

126. Robinson MD, Oshlack A. A scaling normalization method for differential expression analysis of RNA-seq data. Genome Biol. [Internet]. 2010;11:R25. Available from: http://www.pubmedcentral.nih.gov/articlerender.fcgi?artid= 2864565\&tool=pmcentrez\&rendertype=abstract

127. Oliveros JC. Venny. An interactive tool for comparing lists with Venn's diagrams. [Internet]. 2007 [cited 2016 Mar 20]. Available from: http://bioinfogp. cnb.csic.es/tools/venny/index.html

128. Shimodaira H, Hasegawa M. Letter to the Editor Multiple Comparisons of Log-Likelihoods with Applications to Phylogenetic Inference. Mol. Biol. Evol. [Internet]. 1999;16:1114-6. Available from: http://mbe.oxfordjournals.org/ content/16/8/1114.full.pdf+html 